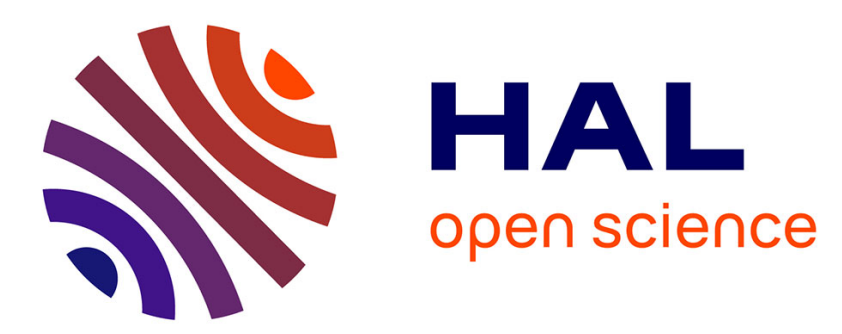

\title{
Electronic spectra of the protonated indole chromophore in the gas phase
}

Ivan Alata, Bert Johan, Michel Broquier, Claude Dedonder, Géraldine Féraud, Gilles Grégoire, Soorkia Satchin, Ernesto Marceca, Christophe Jouvet

\section{- To cite this version:}

Ivan Alata, Bert Johan, Michel Broquier, Claude Dedonder, Géraldine Féraud, et al.. Electronic spectra of the protonated indole chromophore in the gas phase. Journal of Physical Chemistry A, 2013, 117 (21), pp.4420-4427. 10.1021/jp402298y · hal-00724234v2

\section{HAL Id: hal-00724234 \\ https://hal.science/hal-00724234v2}

Submitted on 19 Dec 2013

HAL is a multi-disciplinary open access archive for the deposit and dissemination of scientific research documents, whether they are published or not. The documents may come from teaching and research institutions in France or abroad, or from public or private research centers.
L'archive ouverte pluridisciplinaire HAL, est destinée au dépôt et à la diffusion de documents scientifiques de niveau recherche, publiés ou non, émanant des établissements d'enseignement et de recherche français ou étrangers, des laboratoires publics ou privés. 


\title{
Electronic Spectra of the Protonated Indole Chromophore in the Gas Phase
}

Ivan Alata ${ }^{1,2}$, Johan Bert ${ }^{3}$, Michel Broquier ${ }^{1,4}$, Claude Dedonder $^{1,3}$, Géraldine Feraud ${ }^{3}$, Gilles Grégoire $^{5}$, Satchin Soorkia ${ }^{4}$, Ernesto Marceca ${ }^{6}$, Christophe Jouvet $^{1,3, *}$

1) CLUPS (Centre Laser de I'Université Paris Sud / LUMAT FR 2764), Bât. 106, Univ Paris-Sud 11,91405 Orsay Cedex, France

2) Atomic Energy Commission of Syria, Damascus, P.O. Box 6091 Syria. http://www.aec.org.sy/

3) PIIM, Aix-Marseille Université, UMR-CNRS 7345, Avenue Escadrille Normandie-Niémen, 13397 Marseille cedex 20, France

4) Institut des Sciences Moléculaires d'Orsay (ISMO, UMR 8214 CNRS), Bât. 210, Univ Paris-Sud 11,91405 Orsay Cedex, France

5) Laboratoire de Physique des Lasers, Université Paris 13, Sorbonne Paris Cité, CNRS, 93430 Villetaneuse, France

6) INQUIMAE-FCEN, UBA, Ciudad Universitaria, 3er piso, Pab. II, (1428) Buenos Aires, Argentina

\begin{abstract}
The electronic spectroscopy of cold protonated indole was investigated experimentally and theoretically. Two isomers have been observed in this experiment, the first isomer corresponds to the lowest energy isomer in the calculations, absorbing at $\sim 350 \mathrm{~nm}$ and protonated on the $\mathrm{C}_{3}$ atom of the pyrrole ring. According to our calculations, the absorption of the other isomers protonated on carbon atoms $\left(C_{2}, C_{4}, C_{5}, C_{6}\right.$ and $\left.C_{7}\right)$ is in the visible region. Indeed, the absorption of the second isomer observed starts at $488 \mathrm{~nm}$ and has been assigned to protonation on the $C_{2}$ carbon of the pyrrole ring. Since good agreement was obtained between calculated and experimental transitions for the observed isomers, reasonable $a b$ initio transition energies may also be expected for the higher energy isomers protonated on other carbon atoms, which should also absorb in the visible. Protonation on the nitrogen atom leads to a blue-shifted transition with respect to that of the most stable isomer.
\end{abstract}

Keywords: excited states, photo-fragmentation spectroscopy, cold ion trap, ab initio calculations, protonation sites. 


\section{Introduction}

The spectroscopic properties of indole chromophores have attracted much interest over the last decades ${ }^{1}$ because these molecules can be used as model systems to study the complex photophysics of the amino acid tryptophan (Trp). Photochemical reactions of Trp and Trp residues in proteins play a fundamental role in nature. In particular, fluorescence and phosphorescence of tryptophan residues in proteins are widely used as a tool to monitor a variety of biological processes, giving rise to structural and dynamic information. ${ }^{2-4}$ However, the improvement of these optical probes requires the understanding of the fundamental photochemical processes occurring in the bare $\operatorname{Trp}$ molecule. ${ }^{5-7}$ Of particular interest is the strong $\mathrm{pH}$ dependence observed in the aqueous Trp fluorescence lifetime, which decreases from ns to fs when the molecule is protonated. ${ }^{8}$ The multi-exponential decay observed for Trp in aqueous solution and in proteins has been tentatively explained by the rotamer model, ${ }^{2,6,9,}$ ${ }^{10}$ which states that the lifetime is governed by the $C_{\alpha}-C_{\beta}$ bond torsion.

The quenching of the Trp fluorescence has been suggested to result from an intramolecular hydrogen/proton exchange occurring in the Trp zwitterion, where the alanyl chain curves back over the indole moiety and a proton from the ammonium group is transferred to the $\mathrm{C}_{2}{ }^{8}$ or $\mathrm{C}_{4}{ }^{11}$ carbon (see figure 1 for the atom numbering). This mechanism is corroborated by the fact that the fluorescence of indole compounds is quenched due to the occurrence of an intermolecular excited state proton transfer involving protonation at different sites $\left(\mathrm{C}_{4} \text { or } \mathrm{C}_{7}\right)^{12,13}$

Even though the lifetime of neutral Trp in the gas phase is long, ${ }^{14,}{ }^{15}$ the protonated species exhibits a very short lifetime ${ }^{16-19}$ that has been assigned to the excited state dynamics of the proton. Further evidence that supports the presence of a proton transfer mechanism 
can also be deduced from the fragmentation pattern in which the appearance of a fragment at $\mathrm{m} / \mathrm{z} 132$ (protonated methyl-indole fragment) can only be explained by a proton transfer from the terminal ammonium group $\mathrm{C}-\mathrm{NH}_{3}{ }^{+}$to the indole ring and a second $\mathrm{H}$ transfer ${ }^{20,21}$ as the fragments separate; this process is corroborated by ab initio calculations. ${ }^{22,23}$

Recently, femtosecond pump/probe experiments on tryptophan in solution have assigned the appearance of a transient absorption band in the visible $(425 \mathrm{~nm})$ to the protonated indole photoproduct, on the basis of previous studies. ${ }^{24}$ The validity of this assumption can be tested by investigating the excited states of protonated indole both theoretically and experimentally.

We have measured the electronic spectrum of protonated indole in the gas phase via photo-fragmentation spectroscopy. Two isomers have been detected, one is easily observed in the UV and a second one in the visible region with less intensity. Based on $a b$ initio calculations, the UV spectrum is assigned to the most stable isomer with protonation on $\mathrm{C}_{3}$ carbon (see figure 1 for the atom numbering in indole: the numbering starts on the $N_{1}$ nitrogen atom and turns anti-clockwise on $C_{2}, C_{3}, C_{4}, C_{5}, C_{6}$ and $C_{7}$ carbons, jumping the $C_{8}$ and $\mathrm{C}_{9}$ common to both rings ). The second spectrum in the visible region is assigned to the isomer protonated on $\mathrm{C}_{2}$ carbon. The different isomers will be named according to the protonation site: $\mathrm{NH}^{+}$if the proton is attached to the nitrogen atom or $\mathrm{C}_{n} \mathrm{H}^{+}$if it is attached to the $\mathrm{C}_{\mathrm{n}}$ carbon atom.

Because comparison between theory and experiment is quite good for the observed isomers $\left(\mathrm{C}_{2} \mathrm{H}^{+}\right.$and $\left.\mathrm{C}_{3} \mathrm{H}^{+}\right)$, it seems reasonable to trust $a b$ initio calculations to predict the transitions of the other unobserved isomers. 


\section{Methods}

\section{Experimental}

The electronic spectrum of protonated indole was obtained via photo-fragment spectroscopy of the parent ion in a cryogenic cold quadrupole ion trap (Paul ion trap from Jordan TOF Products, Inc.). The setup is quite similar to the one developed by Wang and Wang. ${ }^{25-27}$ The protonated ions are produced by an electrospray ionization source built at Aarhus university. ${ }^{28}$ At the exit of the capillary, ions are trapped in an octopole trap for $90 \mathrm{~ms}$. They are extracted by applying a negative pulse of $50 \mathrm{~V}$ and are further accelerated to $100 / 200 \mathrm{~V}$ by a second pulsed voltage just after the exit electrode. This time sequence of pulsed voltages produces ion packets with a duration time between 500 ns and $1 \mu$ s. Ions are driven by a couple of electrostatic lenses toward the Paul trap (from Jordan Co) biased at $100 / 200 \mathrm{~V}$ so that the ions enter the trap gently. A mass gate placed at the entrance of the trap allows selecting the parent ion. The Paul trap is mounted on the cold head of a cryostat (Coolpak Oerlikon) connected to a water-cooled He compressor. Helium as buffer gas is injected in the trap using a pulsed valve (General Valve) triggered $1 \mathrm{~ms}$ before the ions enter the trap. The ions are trapped and thermalized at a temperature around 50K through collisions with buffer gas. The ions are kept in the trap for $90 \mathrm{~ms}$ before the photo-dissociation laser is triggered: this delay is necessary to ensure thermalization of ions and evacuation of $\mathrm{He}$ buffer gas from the trap. Under these conditions, ions are not fragmented by collisions when they are extracted and accelerated for analysis in a linear time of flight mass spectrometer of $1.5 \mathrm{~m}$ long. Ions are fragmented in the trap and the delay between laser and extraction has been varied to measure the fragmentation time. The time resolution that can be obtained is around 100 ns. For protonated indole, the fragmentation time is faster than this resolution. Photo-fragmentation spectra are obtained by recording the fragment ion signal on a 
microchannel plates (MCP) detector as a function of laser wavelength with a digitizing storage oscilloscope interfaced to a PC.

The photo-dissociation laser is an OPO laser from EKSPLA, which has a $10 \mathrm{~Hz}$ repetition rate, a resolution of $8 \mathrm{~cm}^{-1}$ and a scanning step of $0.1 \mathrm{~nm}$. The laser is mildly focused in the trap with a $1 \mathrm{~m}$ focal lens and the laser power is around $20 \mathrm{~mW}$ in the UV and $40 \mathrm{~mW}$ in the visible. Part of the UV spectrum has been recorded at the CLUPS facility in Orsay on a similar setup, but using a Nd:YAG pumped dye laser with a higher spectral resolution $\left(0.2 \mathrm{~cm}^{-1}\right)$.

\section{Calculations}

$A b$ initio calculations have been performed with the TURBOMOLE program package, ${ }^{29}$ making use of the resolution-of-the-identity (RI) approximation for the evaluation of the electron-repulsion integrals. ${ }^{30}$ The equilibrium geometry of protonated indole in its ground electronic state $\left(S_{0}\right)$ has been determined at the MP2 (Møller-Plesset second order perturbation theory) level. Excitation energies and equilibrium geometry of the lowest excited singlet state $\left(S_{1}\right)$ have been determined at the RI-CC2 level. Calculations were performed with two basis sets: the correlation-consistent polarized valence double-zeta cc-pVDZ and aug-ccpVDZ basis sets, using in addition for the $\mathrm{C}_{3} \mathrm{H}^{+}$isomer, which exhibits a quite complex vibrational structure, a triple-zeta basis set with diffuse orbital (aug-cc-pVTZ). ${ }^{31}$

The vibrations in the ground and excited states have been calculated and the electronic spectra simulated using PGOPHER software ${ }^{32}$ for the Frank-Condon analysis.

\section{Results}




\section{Experimental}

Clear electronic spectra of protonated indole have been obtained in two spectral regions, one in the visible $(\sim 480 \mathrm{~nm})$ and the other in the UV $(\sim 360 \mathrm{~nm})$ with more intensity. These vibronic spectra have been assigned with the help of $a b$ initio calculations to two different isomers. The UV photo-fragmentation spectrum recorded at $m / z 91$ is presented in Figure 1, the first band at $359.8 \mathrm{~nm}(3.446 \mathrm{eV})$, being assigned to the $0-0$ transition of the $\mathrm{C}_{3} \mathrm{H}^{+}$ isomer (vide infra). Since the results of Yang et al. $^{33}$ show that, in the collision-induced dissociation (CID) of protonated indole with Xenon, a collision energy of at least $5 \mathrm{eV}$ in the center of mass is required to induce fragmentation (mainly through the loss of $\mathrm{HCN}$ ), the spectrum recorded here corresponds to a two-photon absorption. The laser power dependence of the signal has been recorded and shows sign of saturation (See supplementary information). The bandwidth of the band origin is ca. $5 \mathrm{~cm}^{-1}$ (insert of figure 1), indicating that the lower limit of the excited state lifetime is $1 \mathrm{ps.}$ 


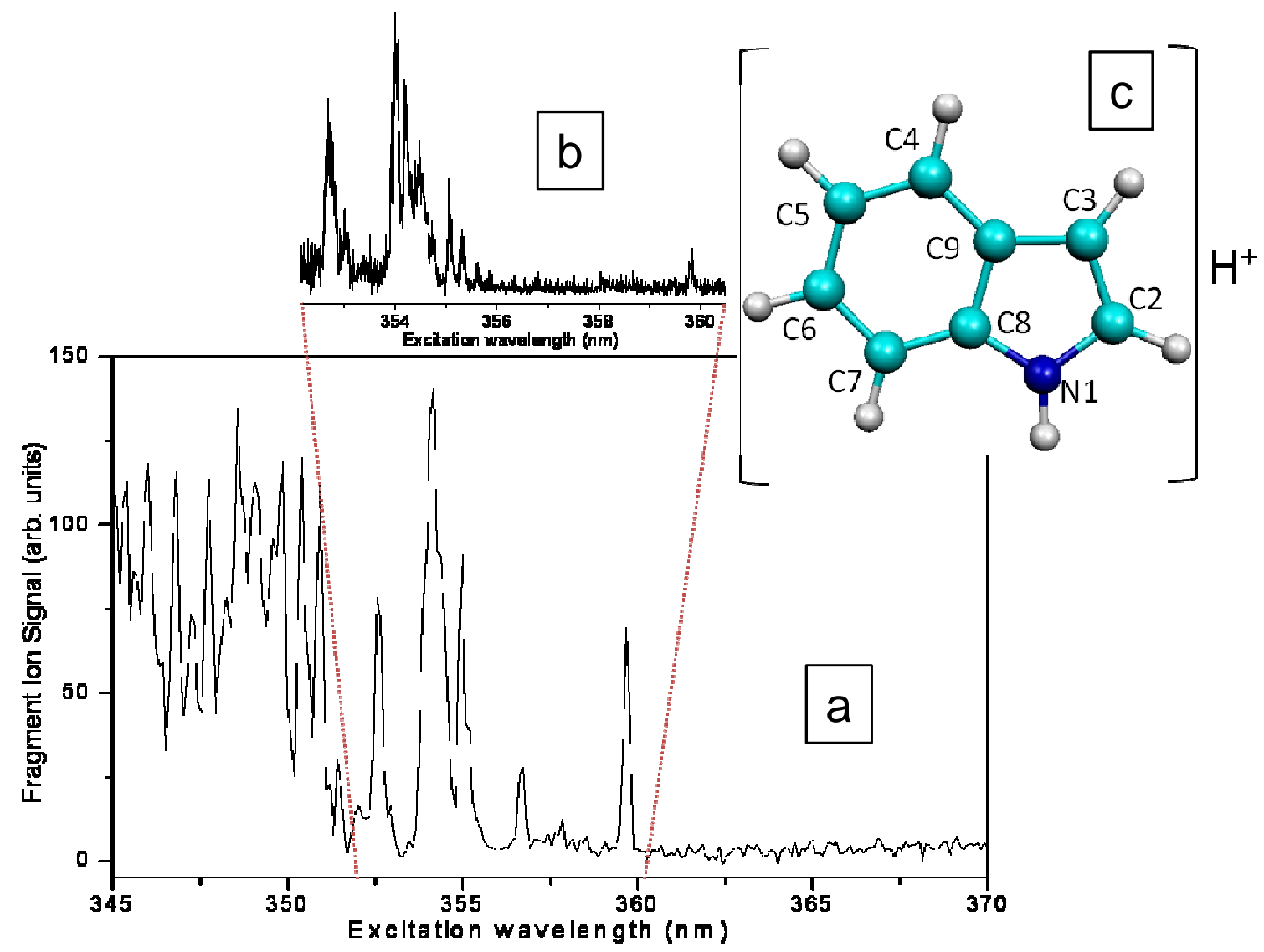

Figure 1: Two-photon photo-fragmentation spectrum of the $\mathrm{C}_{3} \mathrm{H}^{+}$isomer of protonated indole recorded at $\mathrm{m} / \mathrm{z}$ 91: a) spectrum recorded with $8 \mathrm{~cm}^{-1}$ resolution; b) part of the spectrum recorded at higher resolution $\left(0.2 \mathrm{~cm}^{-1}\right)$; c) scheme of the indole molecule with numbering of the carbon atoms. The wavelengths are calibrated to vacuum.

The spectrum recorded at $\mathrm{m} / \mathrm{z} 91$ in the visible region is presented in Figure 2 . In this spectrum, the first band at $488 \mathrm{~nm}(2.54 \mathrm{eV})$ is assigned to the $0-0$ band origin, as no transition is observed further to the red. As previously, the signal comes likely from a twophoton process. We will show in the next section that this spectrum can be assigned to the $\mathrm{C}_{2} \mathrm{H}^{+}$isomer. 


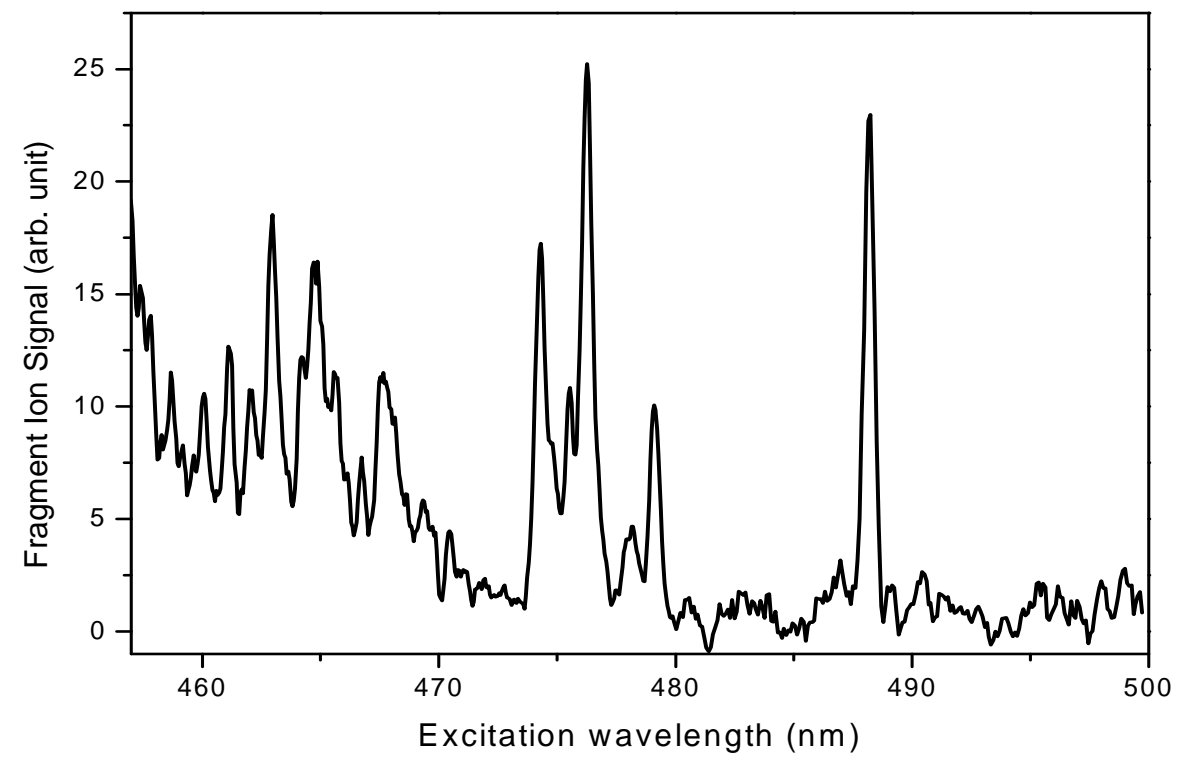

Figure 2: Two-photon photo-fragmentation spectrum of the $\mathrm{C}_{2} \mathrm{H}^{+}$isomer of protonated indole recorded at $\mathrm{m} / \mathrm{z} 91$.

Between these two spectral regions where intense narrow transitions are observed, a signal is observed in the $460-410 \mathrm{~nm}$ spectral region but cannot be resolved. It can be assigned to the absorption of high vibrational levels of the $\mathrm{C}_{2} \mathrm{H}^{+}$isomer or to other isomers. The spectral signature of other isomers has been search for in scanning from $600 \mathrm{~nm}$ to 230 $\mathrm{nm}$, but none could be identified.

The fragmentation channels for the isomers absorbing in the UV and in the visible are presented in Figure 3. The fragmentation channels are not the same for both isomers. The isomer excited in the visible exhibits only the HCN/HNC loss channel as in CID experiments. ${ }^{33}$ ${ }^{34}$ For the isomer excited in the UV, in addition to the HCN/HNC loss channel, the $\mathrm{H}$ loss channel is also observed as well as the loss of $\mathrm{H}+\mathrm{HCN} / \mathrm{HNC}$ and $\mathrm{H}+\mathrm{H}+\mathrm{HCN} / \mathrm{HNC}$, which are not observed in CID at $5 \mathrm{eV}$ of collision energy. ${ }^{33}$ The two latter channels are the main 
fragments obtained from the fragmentation of the indole radical cation, ${ }^{35}$ which strongly suggests that the radical cation produced after the $\mathrm{H}$ loss undergoes further fragmentation, loosing $\mathrm{HCN} / \mathrm{HNC}$ and $\mathrm{H}+\mathrm{HCN} / \mathrm{HNC}$.

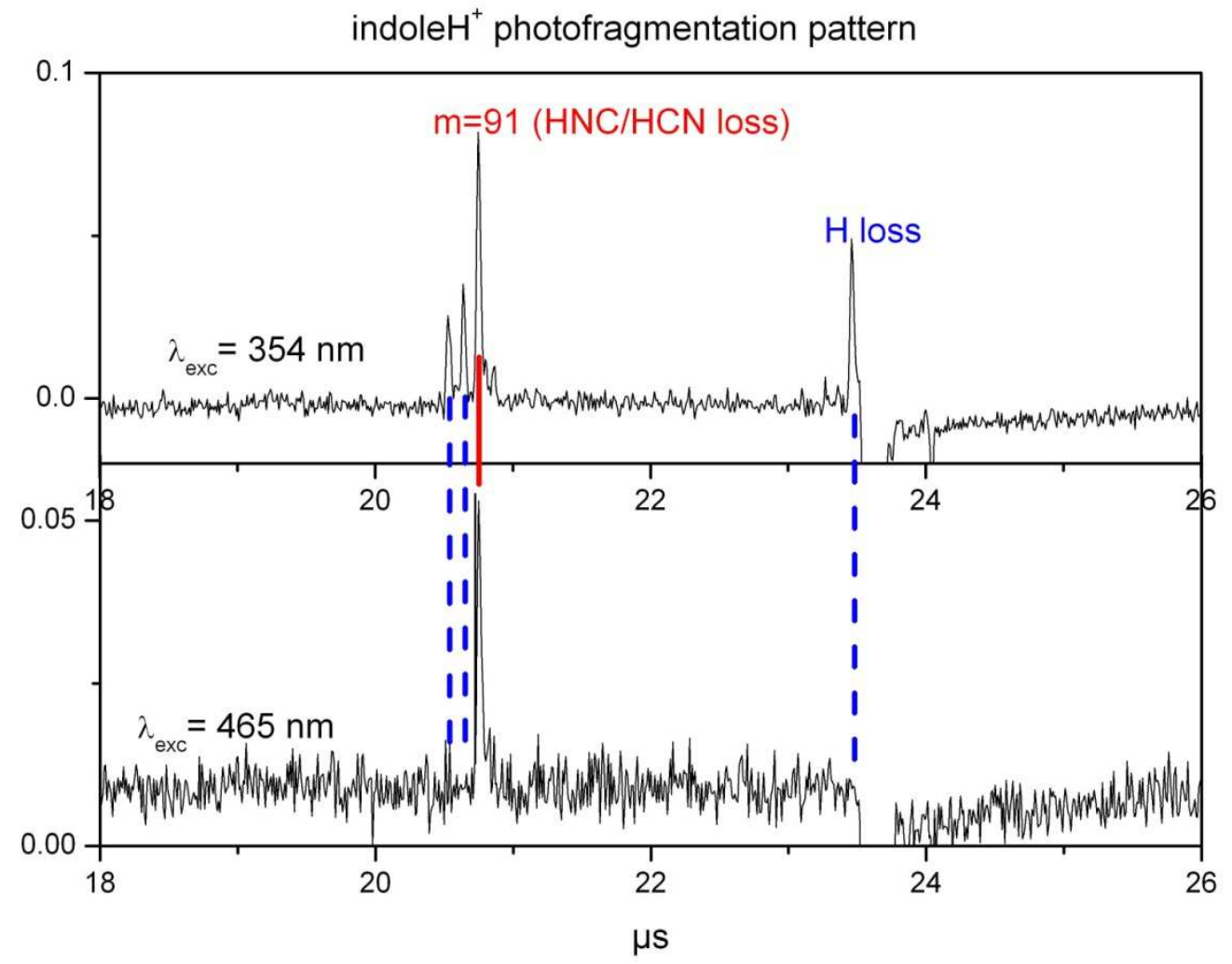

Figure 3: Difference time-of-flight mass spectra (with and without laser) recorded for the two isomers of protonated indole at $354 \mathrm{~nm}$ and $465 \mathrm{~nm}$, respectively.

\section{Calculations}

Ground state calculations at the RI-MP2 and RI-CC2 (cc-pVDZ) level are in good agreement with previous calculations giving the $\mathrm{C}_{3} \mathrm{H}^{+}$isomer as by far the most stable (see table 1). ${ }^{36,37}$ The different isomers are named according to the protonation site: $\mathrm{NH}^{+}$if the proton is attached to the nitrogen atom or $\mathrm{C}_{n} \mathrm{H}^{+}$if it is attached to the $\mathrm{C}_{n}$ carbon atom (see Figure 1 for the atom numbering in indole). The calculated proton affinity is $9.53 \mathrm{eV}$ (919.8 $\mathrm{kJ} / \mathrm{mol}$ ) at the CC2 level, in good agreement with previous calculations ${ }^{36,37}$ and with the 
experimental value of $933.4 \mathrm{~kJ} / \mathrm{mol}^{38}$ The other isomers protonated on external carbon atoms $\left(C_{2}, C_{4}, C_{5}, C_{6}, C_{7}\right)$ are less stable (stabilization energies in the range $\left.0.36-0.57 \mathrm{eV}\right)$.

The vertical and adiabatic transitions calculated at the RI-CC2 (cc-pVDZ) level of theory for the different isomers (except $\mathrm{C}_{8} \mathrm{H}^{+}$and $\mathrm{C}_{9} \mathrm{H}^{+}$) are given in table 1. The isomers protonated on the $C_{8}$ and $C_{9}$ inner carbon atoms are very high in energy as compared to the most stable isomer (more than $1 \mathrm{eV}$ higher) so that these isomers are not expected to be present in the experiment and their transition energies have not been calculated.

Table 1: Ground state relative stabilization energies and excited state transition energies for the protonated indole isomers. All values are in $\mathrm{eV}$.

\begin{tabular}{|c|c|c|c|c|c|c|}
\hline Isomer & Ground state $^{\mathrm{a}}$ & \multicolumn{5}{|c|}{ Excited state transition energy $^{\text {experimental }}$} \\
\hline & $\begin{array}{c}\mathrm{S}_{1} \leftarrow \mathrm{S}_{0} \\
\text { vertical }^{\mathrm{b}}\end{array}$ & $\begin{array}{c}\mathrm{S}_{1} \leftarrow \mathrm{S}_{0} \\
\text { adiabatic }^{\mathrm{c}}\end{array}$ & $\begin{array}{c}\mathrm{S}_{1} \leftarrow \mathrm{S}_{0} \\
\text { adiabatic } \\
\text { with } \delta \mathrm{ZPE}^{\mathrm{d}}\end{array}$ & $\begin{array}{c}\mathrm{S}_{2} \leftarrow \mathrm{S}_{0} \\
\text { vertical }^{\mathrm{b}}\end{array}$ & \\
\hline $\mathrm{C}_{2} \mathrm{H}^{+}$ & 0.36 & 3.24 & 2.76 & 2.62 & 4.98 & 2.54 \\
\hline $\mathrm{C}_{3} \mathrm{H}^{+}$ & $\mathbf{0 . 0 0}$ & 4.09 & 3.49 & 3.33 & 4.25 & 3.45 \\
\hline $\mathrm{C}_{4} \mathrm{H}^{+}$ & 0.46 & 3.37 & 2.86 & 2.73 & 3.82 & \\
\hline $\mathrm{C}_{5} \mathrm{H}^{+}$ & 0.47 & 3.50 & 2.86 & 2.75 & 4.09 & \\
\hline $\mathrm{C}_{6} \mathrm{H}^{+}$ & 0.47 & 3.26 & 2.96 & 2.83 & 4.84 & \\
\hline $\mathrm{C}_{7} \mathrm{H}^{+}$ & 0.57 & 3.25 & 2.40 & 2.31 & 3.70 & \\
\hline $\mathrm{NH}^{+}$ & 0.83 & 4.86 & 4.66 & - & 5.40 & \\
\hline $\mathrm{C}_{8} \mathrm{H}^{+}$ & 1.16 & - & - & - & - & \\
\hline $\mathrm{C}_{9} \mathrm{H}^{+}$ & 1.19 & - & - & - & - & \\
\hline
\end{tabular}

a) Ground state energy relative to the $\mathrm{C}_{3} \mathrm{H}^{+}$isomer calculated at the RI-MP2/cc-pVDZ level.

b) Vertical excited state transition energy at the RI-CC2 /cc-pVDZ level.

c) Adiabatic excited state transition energy at the RI-CC2 /cc-pVDZ level.

d) Adiabatic excited state transition energy corrected for the difference in zero point energy $\delta \mathrm{ZPE}$. For the $\mathrm{C}_{3} \mathrm{H}^{+}$isomer, the calculations have also been done with the aug-cc-pVTZ basis set and the adiabatic transition energy corrected for $\delta Z P E$ decreases to $3.28 \mathrm{eV}$.

As in many aromatic molecules, the difference between the vertical and the adiabatic transition energies obtained by the excited state optimization is quite large ranging from 0.2 $\mathrm{eV}$ for the $\mathrm{NH}^{+}$isomer, $0.85 \mathrm{eV}$ for $\mathrm{C}_{7} \mathrm{H}^{+}$, and $0.6 \mathrm{eV}$ for the most stable $\mathrm{C}_{3} \mathrm{H}^{+}$isomer. This clearly shows that comparison between calculations and experiments requires the excited state optimization, which is too seldom done. The difference in zero point energy between 
the excited and ground state is not negligible ( $\delta \mathrm{ZPE}=-0.17 \mathrm{eV}$ for the $\mathrm{C}_{3} \mathrm{H}^{+}$isomer) and is typical of many aromatic molecules. It has to be taken into account but its evaluation is quite computer time consuming and requires good facilities. When $\delta$ ZPE is taken into account, the transition energy for the $\mathrm{C}_{3} \mathrm{H}^{+}$isomer lowers to $3.33 / 3.28 \mathrm{eV}$ with the cc-pVDZ and aug-ccpVTZ basis set, respectively. This is not too far from the experimental value for the band origin observed at $3.45 \mathrm{eV} . \mathrm{C}_{3} \mathrm{H}^{+}$is the only isomer having its calculated transition energy in the near UV. The other isomers with the proton located on a carbon atom have their calculated transition energies in the visible.

Among the isomers protonated on carbon atoms, the $\mathrm{C}_{2} \mathrm{H}^{+}$isomer is the second lowest in energy $(0.36 \mathrm{eV})$ and its the calculated $\mathrm{S}_{1}-\mathrm{S}_{0}$ electronic transition is the closest from the origin of the spectrum observed in the visible region: the calculated transition energy is 2.62 $\mathrm{eV}$ (cc-pVDZ basis set with correction for $\delta Z P E)$ and the observed visible spectrum starts at $2.54 \mathrm{eV}$. The calculated $\mathrm{S}_{1}-\mathrm{S}_{0}$ electronic transitions for the $\mathrm{C}_{n} \mathrm{H}^{+}$isomers with $\mathrm{n}=4-6$ are in the 2.70-2.90 eV (420-450 $\mathrm{nm})$ energy range and their ground state stabilization energy is $0.46-$ $0.47 \mathrm{eV}$. The $\mathrm{C}_{7} \mathrm{H}^{+}$isomer has higher stabilization energy $(0.57 \mathrm{eV})$ and even lower transition energy $(2.31 \mathrm{eV})$. For all these isomers the transition energies are far to the red of the neutral indole $\mathrm{S}_{1}-\mathrm{S}_{0}$ transition $(4.38 \mathrm{eV}){ }^{39,}{ }^{40}$ Protonation on the nitrogen atom is unfavorable: according to our calculations, the ground state of the $\mathrm{NH}^{+}$isomer is $0.83 \mathrm{eV}$ higher in energy than the $\mathrm{C}_{3} \mathrm{H}^{+}$ground state. This is probably due to a loss of aromaticity occurring when the lone pair becomes involved in the proton binding. Moreover, the $\mathrm{NH}^{+}$isomer is the only one to have a calculated transition energy shifted to the blue $(4.66 \mathrm{eV})$ from the neutral indole $\mathrm{S}_{1}$ So transition.

Since in tryptophan the indole chromophore is attached to the peptidic chain by a C-C bond at the $\mathrm{C}_{3}$ position, complementary calculations have been performed on the protonated 
3-methylindole to test the influence of the $\mathrm{C}-\mathrm{C}$ bond on the electronic properties. The relative ground state stabilities and the transition energies of protonated 3-methylindole compared to protonated indole are presented in Figure 4 and 5 . The most stable protonation site of 3methylindole is on the $C_{3}$ atom as for protonated indole and for this position the calculated proton affinity is $9.43 \mathrm{eV}=909.8 \mathrm{~kJ} / \mathrm{mol}$, slightly smaller than for indole. The main difference between these compounds is that the $\mathrm{NH}^{+}$isomer is more stable in 3-methylindole than in indole, being as stable as the isomers protonated on $C_{6}$ or $C_{7}$ (see Figure 4).

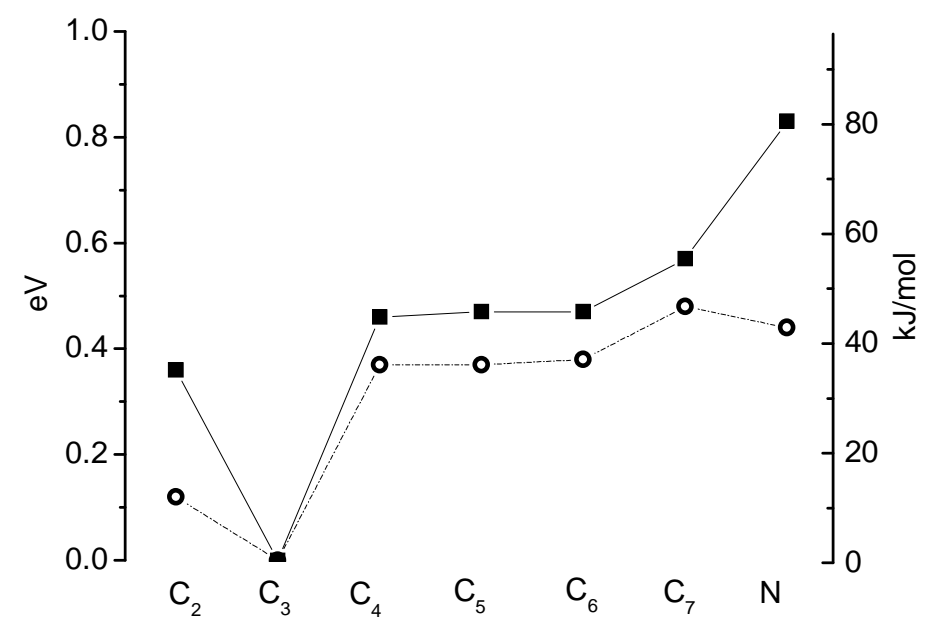

Figure 4: Comparison of the ground state stabilities for the different isomers of protonated 3methylindole (hollow circles) and protonated indole (filled squares).

In the excited state, the transition energies are very similar in protonated 3methylindole and in protonated indole (Figure 5). The $\mathrm{C}_{3} \mathrm{H}^{+}$isomer has a transition energy around $3.5 \mathrm{eV}(350 \mathrm{~nm})$, the $\mathrm{C}_{2} \mathrm{H}^{+}, \mathrm{C}_{4} \mathrm{H}^{+}, \mathrm{C}_{5} \mathrm{H}^{+}$and $\mathrm{C}_{6} \mathrm{H}^{+}$all have a lower transition energy between 2.6 and $3.0 \mathrm{eV}(400-475 \mathrm{~nm})$, the $\mathrm{C}_{7} \mathrm{H}^{+}$isomers have the lowest transition energy at 2.4 and $2.1 \mathrm{eV}$ while protonation on the nitrogen atom leads to a very high transition energy at $4.7 \mathrm{eV}$. 


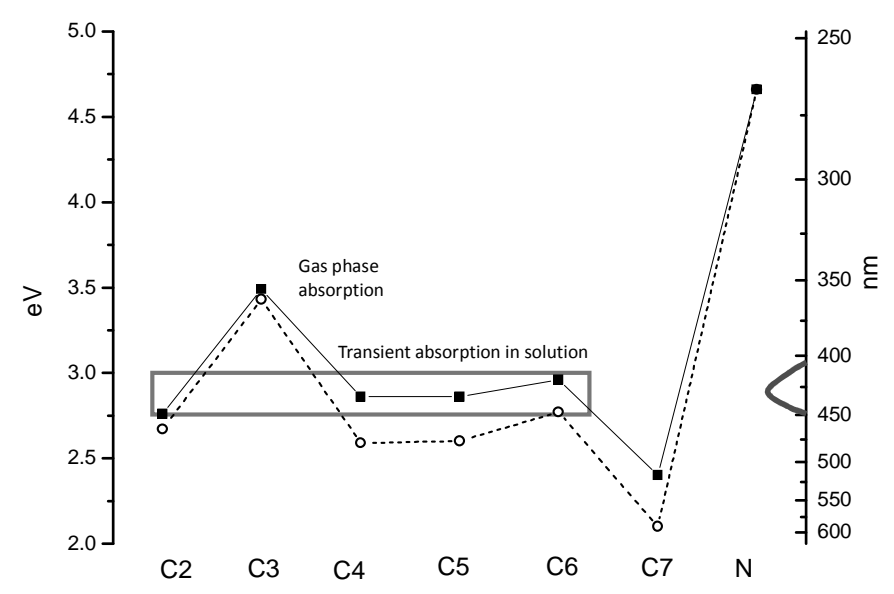

Figure 5: Comparison of the adiabatic transition energies in 3-methylindole (open circles) and indole (filled squares). The rectangle around $425 \mathrm{~nm}$ represents the transient absorption observed for tryptophan in solution, which may be assigned to the $\mathrm{C}_{4} \mathrm{H}^{+}, \mathrm{C}_{5} \mathrm{H}^{+}, \mathrm{C}_{6} \mathrm{H}^{+}$or $\mathrm{C}_{2} \mathrm{H}^{+}$isomers.

As can be seen, the transient absorption observed at $425 \mathrm{~nm}$ in solution (represented by the rectangle in figure 5) and assigned to a primary photo-fragment of tryptophan, can be assigned to isomers of protonated indole, either $\mathrm{C}_{4} \mathrm{H}^{+}, \mathrm{C}_{5} \mathrm{H}^{+}, \mathrm{C}_{6} \mathrm{H}^{+}$or $\mathrm{C}_{2} \mathrm{H}^{+}$.

\section{Discussion}

\section{a) The $\mathrm{C}_{2} \mathrm{H}^{+}$isomer}

As mentioned in the preceding section, the spectrum observed in the visible is assigned to the $\mathrm{C}_{2} \mathrm{H}^{+}$isomer of protonated indole on the basis of the comparison between calculated $(2.62 \mathrm{eV})$ and observed $(2.54 \mathrm{eV})$ transition origins. The assignment is based strongly on the accuracy of $a b$ initio calculations for the excited state transition energy. In previous studies on protonated aromatic molecules, ${ }^{41,42}$ and also on simple closed shell aromatic molecules and clusters (phenol and substituted phenols with ammonia, ${ }^{43}$ 7azaindole with water ${ }^{44}$ ) using the same method (RI-CC2/cc-pVDZ basis set), the comparison 
between theoretical and experimental results is surprisingly good. We did not find systematic deviations but a dispersion between the calculated and the experimental values of about 0.15 eV. Moreover, a recent benchmark study has been done by Send et $a l^{45}$ for a set of different molecules showing that the mean error with the RI-CC2 method is typically $0.1 \mathrm{eV}$ with a dispersion $\sigma=0.15 \mathrm{eV}$.

Additionally, the ground state energy of the $\mathrm{C}_{2} \mathrm{H}^{+}$isomer is calculated at $0.36 \mathrm{eV}$ above the most stable isomer, the other $\mathrm{C}_{n} \mathrm{H}^{+}$isomers $(n=4-7)$ having a ground state energy between 0.46 and $0.57 \mathrm{eV}$. The $\mathrm{C}_{2} \mathrm{H}^{+}$isomer is thus more likely to be observed at low temperature.

The assignment can be corroborated in comparing the observed spectrum to a spectrum simulated in convoluting the calculated Franck-Condon factors with a $10 \mathrm{~cm}^{-1}$ Gaussian function as implemented in the PGOPHER software. As shown in Figure 6, the comparison between simulation and experiment is quite good for the band position, without any scaling factor. The relative intensities are better reproduced if one takes into account the saturation effect by multiplying the calculated intensity by $\left(1-\exp \left(-a^{*} /\right)\right)$ where $a$ is a constant chosen to fit the intensity of the main bands. Since the ground state and the $S_{1}$ state optimized geometries of the $\mathrm{C}_{2} \mathrm{H}^{+}$isomer are both planar, the spectrum is built on one strongly active vibration at $515 \mathrm{~cm}^{-1}$, which correspond to a six-member ring in-plane deformation similar to the $6 a$ vibration of benzene. ${ }^{46}$ The increase of the baseline from 475 $\mathrm{nm}$ to the blue could be due to the spectral congestion, to saturation or possibly to the presence of other isomers (the electronic transitions of the $\mathrm{C}_{4} \mathrm{H}^{+}, \mathrm{C}_{5} \mathrm{H}^{+}$and $\mathrm{C}_{6} \mathrm{H}^{+}$are calculated in this spectral region). 


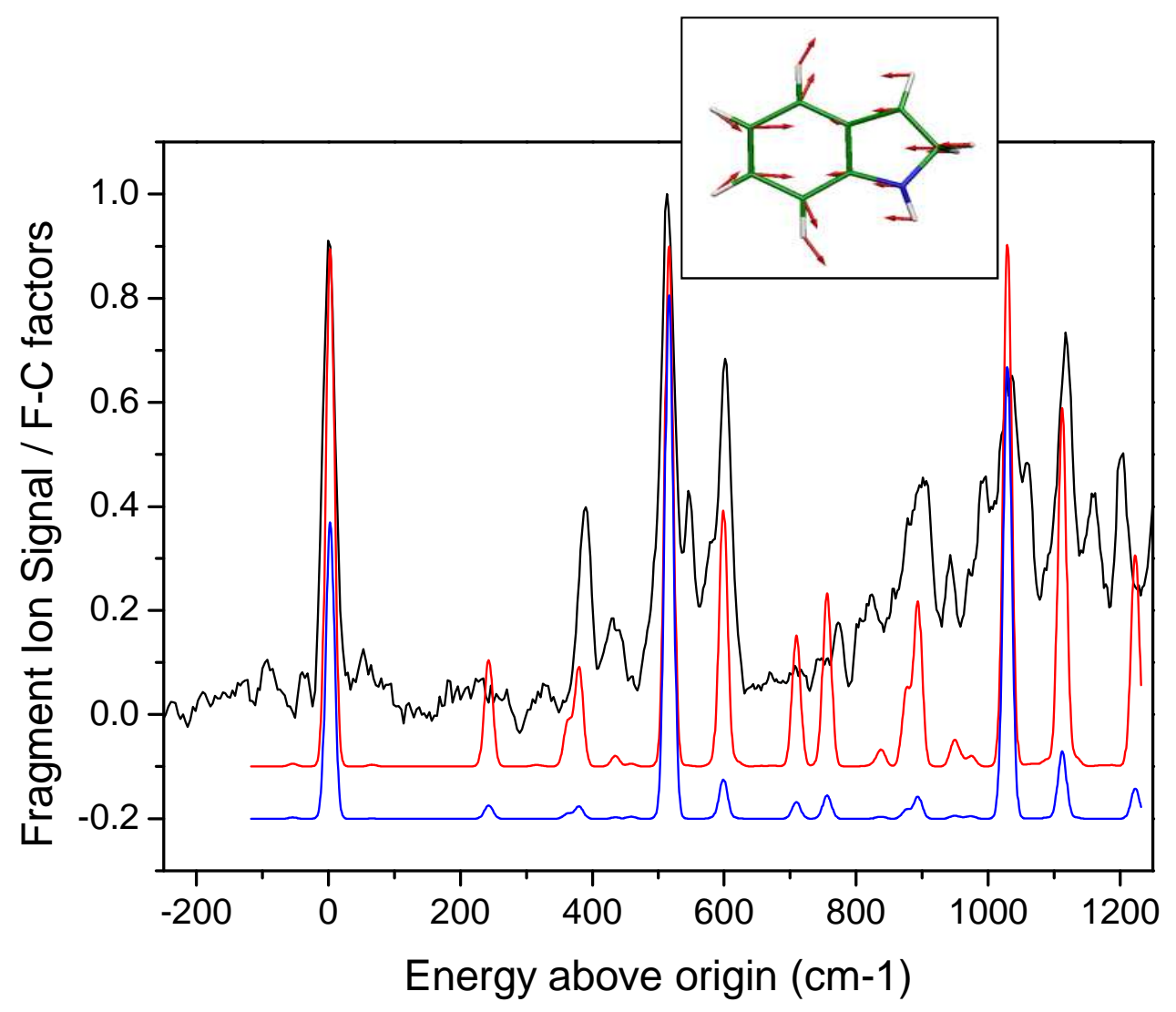

Figure 6: Comparison between experimental and simulated spectra for the $\mathrm{C}_{2} \mathrm{H}^{+}$isomer of protonated indole. Black: experimental spectrum; blue: calculated spectrum at $50 \mathrm{~K}$ without saturation of the bands; red: simulated spectrum at $50 \mathrm{~K}$ adding some saturation in the transitions (see text). Insert: scheme of the most active mode involved in the transition.

For the $\mathrm{C}_{2} \mathrm{H}^{+}$isomer (see Figure 3), only one fragmentation channel corresponding to HNC/HCN loss, which leads to the $\mathrm{m} / \mathrm{z} 91$, is observed.

\section{b) The $\mathrm{C}_{3} \mathrm{H}^{+}$isomer}

For the most stable $\mathrm{C}_{3} \mathrm{H}^{+}$isomer, the calculated optical transition is also in good agreement (within $0.15 \mathrm{eV}$ ) with the observed band origin, but in this case the $\mathrm{S}_{1}$ excited state optimized geometry is not planar, the $C_{2}$ atom lying out of the molecular plane defined by the benzene ring (see Supplementary Information). For this isomer, the two first excited states are very close in energy and the electronic nature of the $S_{1}$ state is changing in the optimization process being $\{55 \%$ [HOMO-1-LUMO] + 40\% [HOMO-LUMO]\} configuration at the ground 
state geometry and 90\% [HOMO-LUMO] at the $S_{1}$ optimized geometry. Using the PGOPHER software, Franck-Condon simulations with several basis sets (cc-pVDZ, aug-cc-pVDZ, and augcc-pVTZ) at the RI-CC2 level of theory were performed. Unlike the $\mathrm{C}_{2} \mathrm{H}^{+}$isomer, the simulated spectrum does not fit well enough with the experimental spectrum. The simulation obtained with the aug-cc-pVTZ basis set is shown on the lower panel of Figure 7. The weak 0-0 transition and the complexity of the spectrum reflect the large change in geometry between the ground and excited states, for which the calculated geometry shows strong out of plane distortions mainly in the pyrrole ring.

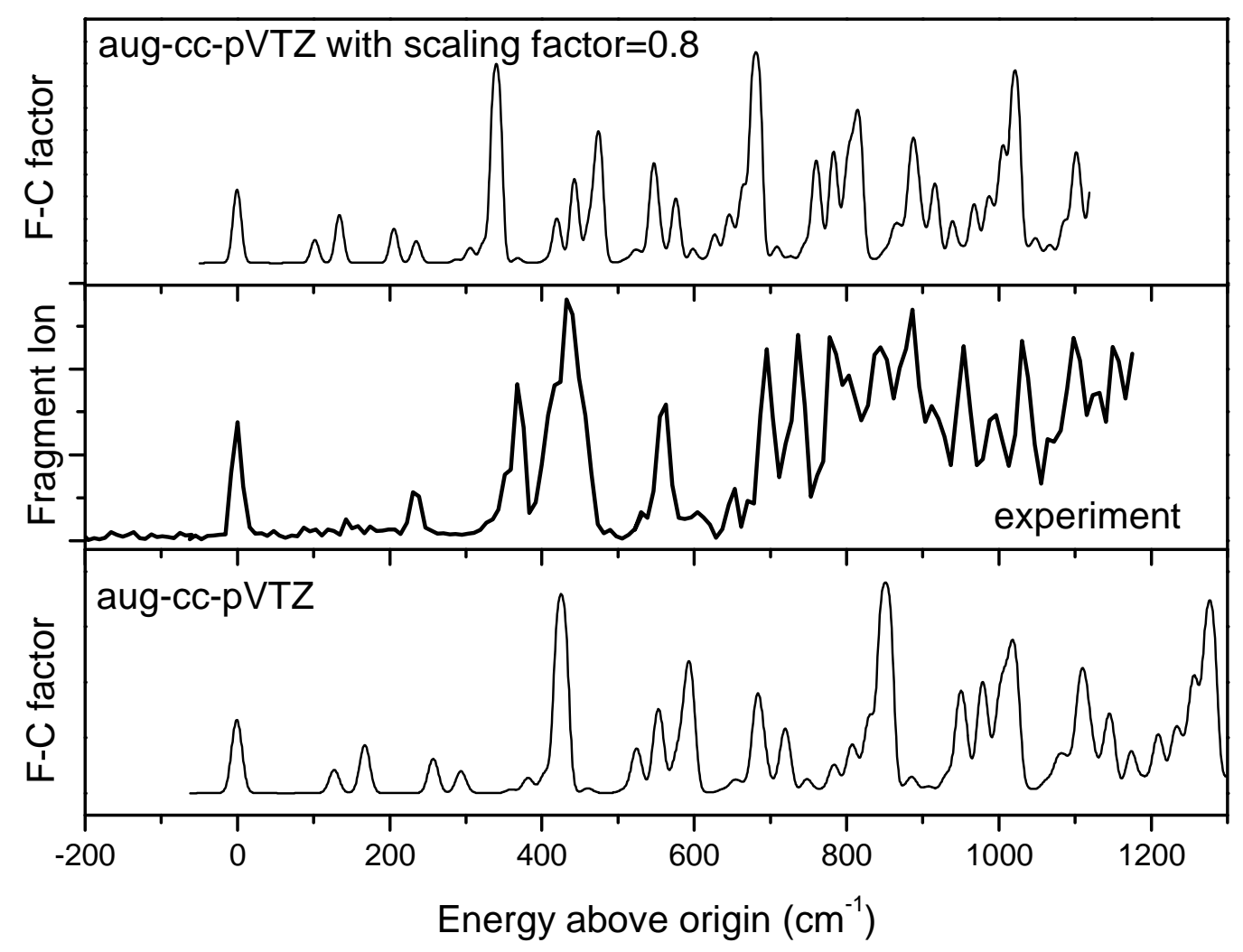

Figure 7: Comparison between experimental and simulated spectra for the $\mathrm{C}_{3} \mathrm{H}^{+}$isomer. Lower trace: simulated spectrum using RI-MP2/CC2 ab initio method with the aug-cc-pVTZ basis set and PGOPHER software for the Franck-Condon simulation. Middle trace: experimental spectrum recorded in the 362-345 $\mathrm{nm}$ range; Upper trace: simulated spectrum using the same method as for the lower trace, with a scaling factor of 0.8 for the excited state frequencies (see text). 
A better agreement between experiment and calculations is obtained if the excited state calculated frequencies are scaled by a factor 0.8 (Figure 7 upper panel), which is greater than the scaling factor generally used for the ground state. Note that this scaling factor is not needed neither to simulate the spectrum of the $\mathrm{C}_{2} \mathrm{H}^{+}$isomer nor the spectra of other aromatic molecules previously studied. ${ }^{41,42,47}$ This could be due to the energetic proximity of the $S_{1}$ and $\mathrm{S}_{2}$ states. Starting from the ground state optimized geometry for which the $\mathrm{S}_{2}$ state is $0.16 \mathrm{eV}$ higher than $S_{1}$, optimization of the $S_{2}$ state leads to a crossing with $S_{1}$ state at an energy of $3.69 \mathrm{eV}$, i.e. $0.2 \mathrm{eV}$ higher than the $\mathrm{S}_{1}$ optimized energy. Further optimization leads back to the $S_{1}$ state optimized geometry and we have not been able to calculate the $S_{2}$ state minimum. The $S_{1}-S_{2}$ Jahn-Teller interaction is going to strongly change the potential energy surfaces of both states and consequently the vibrational frequencies. Under these assumptions, the spectrum seems to be mainly built on the v8 vibrational mode calculated at $425 \mathrm{~cm}^{-1}$ (aug-cc-pVTZ). The $\mathbf{8}_{0}^{1}$ band in the simulated spectrum is the first intense band and can be assigned to the first intense band in the spectrum. The $v 8$ frequency is mainly due to the $\mathrm{N}-\mathrm{H}$ out of plane bending, and its overestimation is probably due to the coupling between $\mathrm{S}_{1}$ and $\mathrm{S}_{2}$.

The fragmentation pattern of this isomer is somewhat surprising (Figure 3). In addition to the $\mathrm{HNC} / \mathrm{HCN}$ loss as in CID experiment, the $\mathrm{H}$ loss channel leading to the radical cation and its fragments is observed. This can be rationalized if one considers that two photons are required for the fragmentation. The $\pi \sigma^{*}$ state, well known to lead to the excited state $\mathrm{H}$ loss in many aromatic molecules ${ }^{48,49}$ is calculated at $7.9 \mathrm{eV}$ in the $\mathrm{C}_{3} \mathrm{H}^{+}$isomer (at the ground state geometry) and can be reached through a two-photon process. This state cannot be reached when exciting the $\mathrm{C}_{2} \mathrm{H}^{+}$isomer because the available energy is not enough with two $2.54 \mathrm{eV}$ photons. 


\section{c) Other isomers}

We have searched for other isomers: in scanning more to the red, between 600 and $490 \mathrm{~nm}$ to find the $\mathrm{C}_{7} \mathrm{H}^{+}$isomer calculated around $2.3 \mathrm{eV}(537 \mathrm{~nm})$ and in scanning in the UV between 290 and $230 \mathrm{~nm}$ for the isomer protonated on the nitrogen atom, without success. The transition energies of the $\mathrm{C}_{4} \mathrm{H}^{+}, \mathrm{C}_{5} \mathrm{H}^{+}, \mathrm{C}_{6} \mathrm{H}^{+}$isomers are calculated to be slightly higher than the transition energy of the $\mathrm{C}_{2} \mathrm{H}^{+}$isomer, in a spectral region where the spectrum of the $\mathrm{C}_{2} \mathrm{H}^{+}$ isomer becomes congested. The $420-450 \mathrm{~nm}$ spectral region has been scanned, but only an unresolved signal could be observed, that can be assigned to high vibrational levels of $\mathrm{C}_{2} \mathrm{H}^{+}$. However, the signal to noise ratio of the experiment does not allow us to exclude completely the presence of these isomers.

All these high energy isomers were not expected to be observed in the experiment. Considering their relative stability, in the initial room temperature solution the population $\mathrm{N}\left(\mathrm{C}_{n} \mathrm{H}^{+}\right)$of the different isomers, apart from the $\mathrm{C}_{3} \mathrm{H}^{+}$isomer, should be negligible $\left(\mathrm{N}\left(\mathrm{C}_{\mathrm{n}} \mathrm{H}^{+}\right) / \mathrm{N}\left(\mathrm{C}_{3} \mathrm{H}^{+}\right)<10^{-6}\right)$. If we take into account that the solution passes through a heated capillary $(400 \mathrm{~K})$, the initial population ratio increases to $\mathrm{N}\left(\mathrm{C}_{n} \mathrm{H}^{+}\right) / \mathrm{N}\left(\mathrm{C}_{3} \mathrm{H}^{+}\right)<10^{-5}$. Based on the population estimates, the observation of the $\mathrm{C}_{2} \mathrm{H}^{+}$isomer is questionable. It can be argued that the recorded signal depends on a number of parameters: the population, the oscillator strength of the transition, the Franck-Condon factors, the laser power, the fragmentation efficiency, etc... Among these parameters, some of them can be measured or calculated but the fragmentation efficiency is unknown.

However, if one assumes that the fragmentation efficiencies are the same for the different isomers (this may be totally wrong), since the Franck-Condon factors for the $\mathrm{C}_{2} \mathrm{H}^{+}$ isomer are nearly 30 times larger than for the $\mathrm{C}_{3} \mathrm{H}^{+}$isomer, and the oscillator strength is four times greater for the $\mathrm{C}_{2} \mathrm{H}^{+}$isomer than for the $\mathrm{C}_{3} \mathrm{H}^{+}$, the observed $\mathrm{N}\left(\mathrm{C}_{2} \mathrm{H}^{+}\right) / \mathrm{N}\left(\mathrm{C}_{3} \mathrm{H}^{+}\right)$population 
ratio would correspond to a temperature of about $550 \pm 100 \mathrm{~K}$, not so far from the temperature of the heated capillary of the ESI.

Another tentative explanation for the observation of the high energy $\mathrm{C}_{2} \mathrm{H}^{+}$isomer relies on the possible activation of the ions during the transfer from the octopole guide to the Paul trap. First, the ions are accelerated at $100 / 200 \mathrm{~V}$ and any collision with the residual gas $\left(P=10^{-5}\right.$ mbar) would increase their internal energy. Second, although the bias voltage of the Paul trap is adjusted to match the kinetic energy of the incoming ions to prevent fragmentation, we cannot exclude that activation through collisions with the He buffer gas occurs. In any case, it seems that, in our experimental conditions, the cooling process is fast enough to relax the vibrational energy and freeze the ions in local minima of the potential energy surface.

The $\mathrm{C}_{7} \mathrm{H}^{+}$isomer is calculated to be in a spectral region (around $530 \mathrm{~nm}$ ) that is not obscured by the presence of other isomers, but it has not been observed. This isomer has a ground state energy of $0.57 \mathrm{eV}$ as compared to the $\mathrm{C}_{3} \mathrm{H}^{+}$isomer: assuming the same temperature as for the $\mathrm{C}_{2} \mathrm{H}^{+}$isomer in the formation process, its population would be 50 times smaller than the $\mathrm{C}_{2} \mathrm{H}^{+}$population, and since the Franck-Condon factors are similar for these two isomers, the $\mathrm{C}_{7} \mathrm{H}^{+}$isomer would not be detected with our signal to noise ratio.

\section{d) Relation with solution studies}

This study has shed light on the optical properties of protonated indole, and can help to see if the transient absorption observed at $425 \mathrm{~nm}$ after the UV excitation of tryptophan in solution is compatible with the formation of protonated indole through excited state proton transfer from the ammonium group toward the $C_{4}$ or $C_{5}$ atom of the indole chromophore. We have seen that there is a good agreement between experiment and calculations for transition energies of the isomers of protonated indole observed in this study $\left(\mathrm{C}_{2} \mathrm{H}^{+}\right.$and $\left.\mathrm{C}_{3} \mathrm{H}^{+}\right)$. From this 
starting point, our calculations can be used to predict (within $\sim 0.15 \mathrm{eV}$ ) the electronic absorption of the other isomers. The calculations give transitions around $425 \mathrm{~nm}$ for the $\mathrm{C}_{4} \mathrm{H}^{+}$ and $\mathrm{C}_{5} \mathrm{H}^{+}$isomers of protonated indole and around $480 \mathrm{~nm}$ for the same isomers of protonated 3-methylindole, which compares quite favorably with the transient spectrum observed in solution after photo-excitation of tryptophan. However, one should keep in mind that the calculations correspond to isolated molecules in the gas phase whereas the Trp photo-excitation was a solution phase study, for which strong solvatochromic effects may be expected, which cannot be accounted for in the present calculation.

Previous calculations on possible photo-induced reactions in the excited state of protonated tryptophan have shown that a proton transfer reaction could occur toward the $\mathrm{C}_{4}$ or $C_{2}$ sites. ${ }^{23}$ Protonation at the $C_{2}$ site is also compatible with a transient absorption around $425 \mathrm{~nm}$ since the gas phase absorption of the $\mathrm{C}_{2} \mathrm{H}^{+}$isomer starts at $488 \mathrm{~nm}$ in the gas phase and extends to the blue.

\section{Conclusion}

Among the protonated indole isomers, the most stable is the $\mathrm{C}_{3} \mathrm{H}^{+}$isomer. Its adiabatic transition energy is calculated at $3.33(3.28) \mathrm{eV}$, which compares rather well with the experimental spectrum starting at $3.45 \mathrm{eV}$. The other isomers protonated on external carbon atoms $\left(C_{2}, C_{4}, C_{5}, C_{6}\right)$ have higher stabilization energies and their transition energies are calculated in the $2.62-2.83 \mathrm{eV}(440-470 \mathrm{~nm})$ energy range, significantly different from the absorption region of the $\mathrm{C}_{3} \mathrm{H}^{+}$isomer. Surprisingly, the $\mathrm{C}_{2} \mathrm{H}^{+}$isomer, which has the second lowest ground state stabilization energy $\left(0.36 \mathrm{eV}\right.$ higher than the $\mathrm{C}_{3} \mathrm{H}^{+}$isomer), has been clearly observed with a transition starting at $2.54 \mathrm{eV}$ and a vibronic spectrum that becomes crowded above $2.70 \mathrm{eV}$, where the transitions of the isomers $\mathrm{C}_{4} \mathrm{H}^{+}, \mathrm{C}_{5} \mathrm{H}^{+}, \mathrm{C}_{6} \mathrm{H}^{+}$should appear. 
We thus cannot tell whether these isomers are present or not under our experimental conditions. The absorption of the $\mathrm{C}_{7} \mathrm{H}^{+}$isomer corresponds to an even lower transition energy (2.40 eV), a higher ground state stabilization energy $(0.57 \mathrm{eV})$, and has not been observed. For all these isomers the transition energies are far to the red from the $\mathrm{S}_{1}-\mathrm{S}_{0}$ transition of neutral indole. Protonation on the nitrogen atom also leads to high stabilization energy $(0.83 \mathrm{eV}$ higher than the $\mathrm{C}_{3} \mathrm{H}^{+}$isomer) and it is the only isomer having a transition energy calculated to the blue of that of the most stable isomer.

The hypothesis of a proton transfer reaction from the ammonium group to the indole chromophore in photo-excited tryptophan has been postulated in a number of experimental and theoretical studies. The present calculations are in good agreement with the experimental data for the indole isomers protonated on $C_{3}$ and $C_{2}$, so that, on the basis of such calculations, the assignment of the $425 \mathrm{~nm}$ transient absorption to the indole photo-fragment protonated on $\mathrm{C}_{4}, \mathrm{C}_{5}$ or $\mathrm{C}_{2}$ seems reasonable.

\section{Acknowledgements}

This work has been supported by the Université Paris-Sud 11, by the ANR research Grant (ANR2010BLANC040501), the RTRA "triangle de la physique" COMOVA and the ECOS France-Argentina cooperation program (A11E02). I.A. thanks the Atomic Energy Commission of Syria for financial support. We acknowledge the use of the computing facility cluster GMPCS of the LUMAT federation (FR LUMAT 2764).

\section{Supplementary Information}

Experimental set-up; laser power dependence of the photo-fragmentation signal; calculated geometries for the $\mathrm{C}_{3} \mathrm{H}^{+}$and $\mathrm{C}_{2} \mathrm{H}^{+}$isomers; complementary calculations on 3-methylindole. This material is available free of charge via the Internet at http://pubs.acs.org. 


\section{References}

1. Lumry, R.; Hershberger, M., Status of indole photochemistry with special reference tobiological applications Photochem. Photobiol. 1978, 27, (6), 819-840.

2. Lakowicz, J. R., Principles of Fluorescence Spectroscopy, 2nd ed. Kluwer Academic/Plenum: New York, 1999.

3. Vivian, J. T.; Callis, P. R., Mechanisms of Tryptophan Fluorescence Shifts in Proteins. Biophys. J 2001, 80, (5), 2093-2109.

4. $\quad$ Callis, P. R.; Liu, T., Quantitative Prediction of Fluorescence Quantum Yields for Tryptophan in Proteins. J. Phys. Chem. B. 2004, 108, (14), 4248-4259.

5. Papp, S.; Vanderkooi, J. M., Tryptophan phosphorescence at room temperature as a tool to study protein structure and dynamics. Photochem. Photobiol. 1989, 49, (6), 775-784.

6. Creed, D., The photophysics and photochemistry of the near-UV absorbing amino acids-I. tryptophan and its simple derivatives Photochem. Photobiol. 1984, 39, (4), 537-562.

7. Bent, D. V.; Hayon, E., Excited State Chemistry of Aromatic Amino Acids and Related Peptides. 111. Tryptophan. J. Am. Chem. Soc. 1975, 97, (10), 2612-2619.

8. Robbins, R. J.; Fleming, G. R.; Beddard, G. S.; Robinson, G. W.; Thistlethwaite, P. J.; Woolfe, G. J., Photophysics of Aqueous Tryptophan: $\mathrm{pH}$ and Temperature Effects. J. Am. Chem. Soc. 1980, 102, (20), 6271-6279.

9. Szabo, A. G.; Rayner, D. M., Fluorescence decay of tryptophan conformers in aqueous solution. J. Am. Chem. Soc. 1980, 102, 554-563.

10. Petrich, J. W.; Chang, M. C.; McDonald, D. B.; Fleming, G. R., .On the origin of nonexponential fluorescence decay in tryptophan and its derivatives. J. Am. Chem. Soc. 1983, 105, 3824-3832.

11. Saito, I.; Sugiyama, H.; Yamamoto, A.; Muramatsu, S.; Matsuura, T., Photoinduced reactions. 158. Photochemical hydrogen-deuterium exchange reaction of tryptophan. The role of nonradiative decay of singlet tryptophan. J. Am. Chem. Soc. 1984, 106, (15), 4286-4287.

12. Chen, Y.; Liu, B.; Barkley, M. D., Trifluoroethanol Quenches Indole Fluorescence by ExcitedState Proton Transfer. J. Am. Chem. Soc. 1995, 117, 5608-5609.

13. Yu, H.-T.; Colucci, W. J.; McLaughlin, M. L.; Barkley, M. D., Fluorescence quenching in indoles by excited-state proton transfer. J. Am. Chem. Soc. 1992, 114, 8449-8454.

14. Rizzo, T. R.; Park, Y. D.; Peteanu, L. A.; Levy, D. H., The electronic spectrum of the amino acid tryptophan in the gas phase J. Chem. Phys. 1986, 84, (5), 2534-2541.

15. Philips, L. A.; Webb, S. P.; Martinez III, S. J.; Fleming, G. R.; Levy, D. H., Time-resolved spectroscopy of tryptophan conformers in a supersonic jet. J. Am. Chem. Soc. 1988, 110, 1352-1355.

16. Boyarkin, O. V.; Mercier, S. R.; Kamariotis, A.; Rizzo, T. R., Electronic Spectroscopy of Cold, Protonated Tryptophan and Tyrosine. J. Am. Chem. Soc. 2006, 128, 2816-2817.

17. Kang, H.; Dedonder-Lardeux, C.; Jouvet, C.; Gregoire, G.; Desfrancois, C.; Schermann, J. P.; Barat, M.; Fayeton, J. A., Control of bond-cleaving reactions of free protonated tryptophan ion by femtosecond laser pulses. J. Phys. Chem. A 2005, 109, (11), 2417-2420.

18. Kang, H.; Jouvet, C.; Dedonder-Lardeux, C.; Martrenchard, S.; Gregoire, G.; Desfrancois, C.; Schermann, J. P.; Barat, M.; Fayeton, J. A., Ultrafast deactivation mechanisms of protonated aromatic amino acids following UV excitation Phys. Chem. Chem. Phys. 2005, 7, (2), 394-398.

19. Rizzo, T. R.; Stearns, J. A.; Boyarkin, O. V., Spectroscopic studies of cold, gas-phase biomolecular ions. International Reviews in Physical Chemistry 2009, 28, (3), 481-515.

20. Lepere, V.; Lucas, B.; Barat, M.; Fayeton, J.; Picard, V.; Jouvet, C.; Carcabal, P.; Nielsen, I.; Dedonder-Lardeux, C.; Gregoire, G.; Fujii, A., : Comprehensive characterization of the photodissociation pathways of protonated tryptophan J. Chem. Phys. 2007, 127, (13), 134313.

21. Lucas, B.; Barat, M.; Fayeton, J.; Perot, M.; Jouvet, C.; Gregoire, G.; Nielsen, S., Mechanisms of photoinduced $\mathrm{C}$ (alpha)- $\mathrm{C}$ (beta) bond breakage in protonated aromatic amino acids. J. Chem. Phys. 2008, 128, (16), 164302. 
22. Blancafort, L.; Gonzalez, D.; Olivucci, M.; Robb, M. A., Quenching of tryptophan (1)(pi,pi(star)) fluorescence induced by intramolecular hydrogen abstraction via an aborted decarboxylation mechanism J. Am. Chem. Soc. 2002, 124, 6398-6406.

23. Gregoire, G.; Jouvet, C.; Dedonder, C.; Sobolewski, A. L., Ab initio Study of the Excited-State Deactivation Pathways of Protonated Tryptophan and Tyrosine. J. Am. Chem. Soc. 2007, 129, 62236231.

24. Sharma, D.; Léonard, J.; Haacke, S., Ultrafast excited-state dynamics of tryptophan in water observed by transient absorption spectroscopy. Chem. Phys. Lett. 2010, 489, 99-102.

25. Wang, X.-B.; Wang, L.-S., Development of a low-temperature photoelectron spectroscopy instrument using an electrospray ion source and a cryogenically controlled ion trap. Rev. Scient. Inst. 2008, 79, (7), 073108.

26. Choi, C. M.; Choi, D. H.; Kim, N. J.; Heo, J., Effective temperature of protonated tyrosine ions in a cold quadrupole ion trap. Int. J. Mass Spectrom. 2012, 314, 18-21.

27. Kamrath, M. Z.; Garand, E.; Jordan, P.; Leavitt, C. M.; Wolk, A. B.; Van Stipdonk, M. J.; Miller, S. J.; Johnson, M. A., Vibrational characterization of simple peptides using cryogenic infrared photodissociation of H2-tagged, mass-selected ions. J. Am. Chem. Soc. 2011, 133, (16), 6440-6448.

28. Andersen, J. U.; Hvelplund, P.; Nielsen, S. B.; Tomita, S.; Wahlgreen, H.; Møller, S. P.; Pedersen, U. V.; Forster, J. S.; Jørgensen, T. J. D., The combination of an electrospray ion source and an electrostatic storage ring for lifetime and spectroscopy experiments on biomolecules. Rev. Scient. Instr. 2002, 73, (3), 1284-1287.

29. Ahlrichs, R.; Bar, M.; Haser, M.; Horn, H.; Kolmel, C., Electronic-Structure Calculations on Workstation Computers - The Program System TURBOMOLE. Chem. Phys. Lett., 1989, 162, 165-169.

30. Weigend, F.; Haser, M., RI-MP2: first derivatives and global consistency Theor. Chem. Acc. 1997, 97, 331-340.

31. Dunning, T. H., Gaussian-basis sets for use in correlated molecular calculations.1. the atoms boron through neon and hydrogen J. Chem. Phys. 1989, 90, (2), 1007-1023.

32. Western, C. M., PGOPHER, a Program For Simulating Rotational Structure, University of Bristol, UK, (http://pgopher.chm.bris.ac.uk). .

33. Yang, Z. B.; Ruan, C.; Ahmed, H.; Rodgers, M. T., Probing the potential energy landscape for dissociation of protonated indole via threshold collision-induced dissociation and theoretical studies Int. J. Mass Spectrom. 2007, 265, (2-3), 388-400.

34. Sindona, G.; Uccella, N.; Stahl, D., Reaction mechanisms of gaseous organic ions. Part 22 sructure and reactivity of protonated indole in the gas phase by MS/MS. Int. J. Mass Spectrom. Ion Process. 1985, 63, 49-58.

35. Corval, M., An electron impact study of $\mathrm{HCN}$ elimination from indole by use of $13 \mathrm{C}$ labelling. Org. Mass Spectrom. 1981, 16, (10), 444-447.

36. Somers, K. R. F.; Kryachko, E. S.; Ceulemans, A., Theoretical study of indole: protonation, indolyl radical, tautomers

of indole, and its interaction with water. Chem. Phys. 2004, 301, 61-79.

37. Otero, N.; Gonzalez Moa, M. J.; Mandado, M.; Mosquera, R. A., QTAIM study of the protonation of indole. Chem. Phys. Lett., 2006, 428 249-254.

38. Hunter, E. P.; Lias, S. G., Evaluated Gas Phase Basicities and Proton Affinities of Molecules: An Update,. J. Phys. Chem. Ref. Data 1998, 27, (3), 413-656.

39. Arnold, S.; Sulkes, M., Fluorescence lifetimes of jet-cooled carbonyl-substituted indoles. Evidence of intramolecular charge transfer quenching Original Research Article. Chem. Phys. Lett. 1992, 200, (1-2), 125-129.

40. Hager, J. W.; Demmer, D. R.; Wallace, S. C., Electronic spectra of jet-cooled indoles: evidence for the 1La state. J. Phys. Chem., 1987, 91, (6), 1375-1382.

41. Alata, I.; Omidyan, R.; Broquier, M.; Dedonder, C.; Dopfer, O.; Jouvet, C., Effect of protonation on the electronic structure of aromatic molecules: naphthaleneH(+) Phys. Chem. Chem. Phys. 2010, 12, (43), 14456-14458. 
42. Alata, I.; Omidyan, R.; Dedonder, C.; Broquier, M.; Jouvet, C., Electronically excited states of protonated aromatic molecules: benzaldehyde Phys. Chem. Chem. Phys. 2009, 11, (48), 11479-11486.

43. Pino, G. A.; Oldani, A. N.; Marceca, E.; Fujii, M.; Ishiuchi, S.-I.; Miyazaki, M.; Broquier, M.; Dedonder, C.; Jouvet, C., Excited state hydrogen transfer dynamics in substituted phenols and their complexes with ammonia: $\pi \pi *-\pi \sigma *$ energy gap propensity and ortho-substitution effect

J. Chem. Phys. 2010, 133, 124313.

44. Sakota, K.; Jouvet, C.; Dedonder, C.; Fujii, M.; Sekiya, H., Excited-State Triple-Proton Transfer in 7-Azaindole(H2O)2 and Reaction Path Studied by Electronic Spectroscopy in the Gas Phase and Quantum Chemical Calculations J. Phys. Chem. A 2010, 114, 11161-11166.

45. Send, R.; Kuehn, M.; Furche, F., Assessing Excited State Methods by Adiabatic Excitation Energies. J. Chem. Theory Comput. 2011, 7, (8), 2376-2386

46. Wilson Jr, E. B., The Normal Modes and Frequencies of Vibration of the Regular Plane Hexagon Model of the Benzene Molecule. Phys. Rev. 1934, 45, 706-714.

47. Alata, I.; Broquier, M.; Dedonder, C.; Jouvet, C.; Marceca, E., Electronic excited states of protonated aromatic molecules: Protonated Fluorene. Chem. Phys. 2012, 393 (1), 25-31

48. Dedonder-Lardeux, C.; Grosswasser, D.; Jouvet, C.; Martrenchard, S., Dissociative hydrogen transfer in indole-(NH3)(n) clusters. PhysChem Comm. 2001, 4, 21-23

49. Sobolewski, A. L.; Domcke, W.; Dedonder-Lardeux, C.; Jouvetc, C., Excited-state hydrogen detachment and hydrogen transfer driven by repulsive $1 \pi \sigma^{*}$ states: A new paradigm for nonradiative decay in aromatic biomolecules. Phys. Chem. Chem. Phys. 2002, 4, 1093-1100. 


\section{Tables}

Table 1: Ground state relative stabilization energies and excited state transition energies for the protonated indole isomers. All values are in $\mathrm{eV}$.

\begin{tabular}{|c|c|c|c|c|c|c|}
\hline Isomer & Ground state $^{\mathrm{a}}$ & \multicolumn{5}{|c|}{ Excited state transition energy $^{\text {experimental }}$} \\
\hline & $\begin{array}{c}\mathrm{S}_{1} \leftarrow \mathrm{S}_{0} \\
\text { vertical }\end{array}$ & $\begin{array}{c}\mathrm{S}_{1} \leftarrow \mathrm{S}_{0} \\
\text { adiabatic }^{\mathrm{c}}\end{array}$ & $\begin{array}{c}\mathrm{S}_{1} \leftarrow \mathrm{S}_{0} \\
\text { adiabatic } \\
\text { with } \delta \mathrm{ZPE}^{\mathrm{d}}\end{array}$ & $\begin{array}{c}\mathrm{S}_{2} \leftarrow \mathrm{S}_{0} \\
\text { vertical }\end{array}$ & \\
\hline $\mathrm{C}_{2} \mathrm{H}^{+}$ & 0.36 & 3.24 & 2.76 & 2.62 & 4.98 & 2.54 \\
\hline $\mathrm{C}_{3} \mathrm{H}^{+}$ & $\mathbf{0 . 0 0}$ & $\mathbf{4 . 0 9}$ & $\mathbf{3 . 4 9}$ & $\mathbf{3 . 3 3}$ & $\mathbf{4 . 2 5}$ & $\mathbf{3 . 4 5}$ \\
\hline $\mathrm{C}_{4} \mathrm{H}^{+}$ & 0.46 & 3.37 & 2.86 & 2.73 & 3.82 & \\
\hline $\mathrm{C}_{5} \mathrm{H}^{+}$ & 0.47 & 3.50 & 2.86 & 2.75 & 4.09 & \\
\hline $\mathrm{C}_{6} \mathrm{H}^{+}$ & 0.47 & 3.26 & 2.96 & 2.83 & 4.84 & \\
\hline $\mathrm{C}_{7} \mathrm{H}^{+}$ & 0.57 & 3.25 & 2.40 & 2.31 & 3.70 & \\
\hline $\mathrm{NH}^{+}$ & 0.83 & 4.86 & 4.66 & - & 5.40 & \\
\hline $\mathrm{C}_{8} \mathrm{H}^{+}$ & 1.16 & - & - & - & - & \\
\hline $\mathrm{C}_{9} \mathrm{H}^{+}$ & 1.19 & - & - & - & - & \\
\hline
\end{tabular}

a) Ground state energy relative to the $\mathrm{C}_{3} \mathrm{H}^{+}$isomer calculated at the RI-MP2/cc-pVDZ level.

b) Vertical excited state transition energy at the RI-CC2 /cc-pVDZ level.

c) Adiabatic excited state transition energy at the RI-CC2 /cc-pVDZ level.

d) Adiabatic excited state transition energy corrected for the difference in zero point energy $\delta \mathrm{ZPE}$. For the $\mathrm{C}_{3} \mathrm{H}^{+}$isomer, the calculations have also been done with the aug-cc-pVTZ basis set and the adiabatic transition energy corrected for $\delta Z P E$ decreases to $3.28 \mathrm{eV}$. 


\section{Figure Caption}

Figure 1: Two-photon photo-fragmentation spectrum of the $\mathrm{C}_{3} \mathrm{H}^{+}$isomer of protonated indole recorded at $\mathrm{m} / \mathrm{z}$ 91: a) spectrum recorded with $8 \mathrm{~cm}^{-1}$ resolution; b) part of the spectrum recorded at higher resolution $\left(0.2 \mathrm{~cm}^{-1}\right)$; c) scheme of the indole molecule with numbering of the carbon atoms. The wavelengths are calibrated to vacuum.

Figure 2: Two-photon photo-fragmentation spectrum of the $\mathrm{C}_{2} \mathrm{H}^{+}$isomer of protonated indole recorded at $\mathrm{m} / \mathrm{z} 91$.

Figure 3: Difference time-of-flight mass spectra (with and without laser) recorded for the two isomers of protonated indole at $354 \mathrm{~nm}$ and $465 \mathrm{~nm}$, respectively.

Figure 4: Comparison of the ground state stabilities for the different isomers of protonated 3methylindole (hollow circles) and protonated indole (filled squares).

Figure 5: Comparison of the adiabatic transition energies in 3-methylindole (open circles) and indole (filled squares). The rectangle around $425 \mathrm{~nm}$ represents the transient absorption observed for tryptophan in solution, which may be assigned to the $\mathrm{C}_{4} \mathrm{H}^{+}, \mathrm{C}_{5} \mathrm{H}^{+}, \mathrm{C}_{6} \mathrm{H}^{+}$or $\mathrm{C}_{2} \mathrm{H}^{+}$isomers.

Figure 6: Comparison between experimental and simulated spectra for the $\mathrm{C}_{2} \mathrm{H}^{+}$isomer. Black: experimental spectrum; blue: calculated spectrum without saturation of the bands; red: simulated spectrum adding some saturation in the transitions (see text). Insert: scheme of the most active mode involved in the transition. 
Figure 7: Comparison between experimental and simulated spectra for the $\mathrm{C}_{3} \mathrm{H}^{+}$isomer. Lower trace: simulated spectrum using RI-MP2/CC2 ab initio method with the aug-cc-pVTZ basis set and PGOPHER software for the Franck-Condon simulation. Middle trace: experimental spectrum recorded in the $362-345 \mathrm{~nm}$ range; Upper trace: simulated spectrum using the same method as for the lower trace, with a scaling factor of 0.8 for the excited state frequencies (see text). 


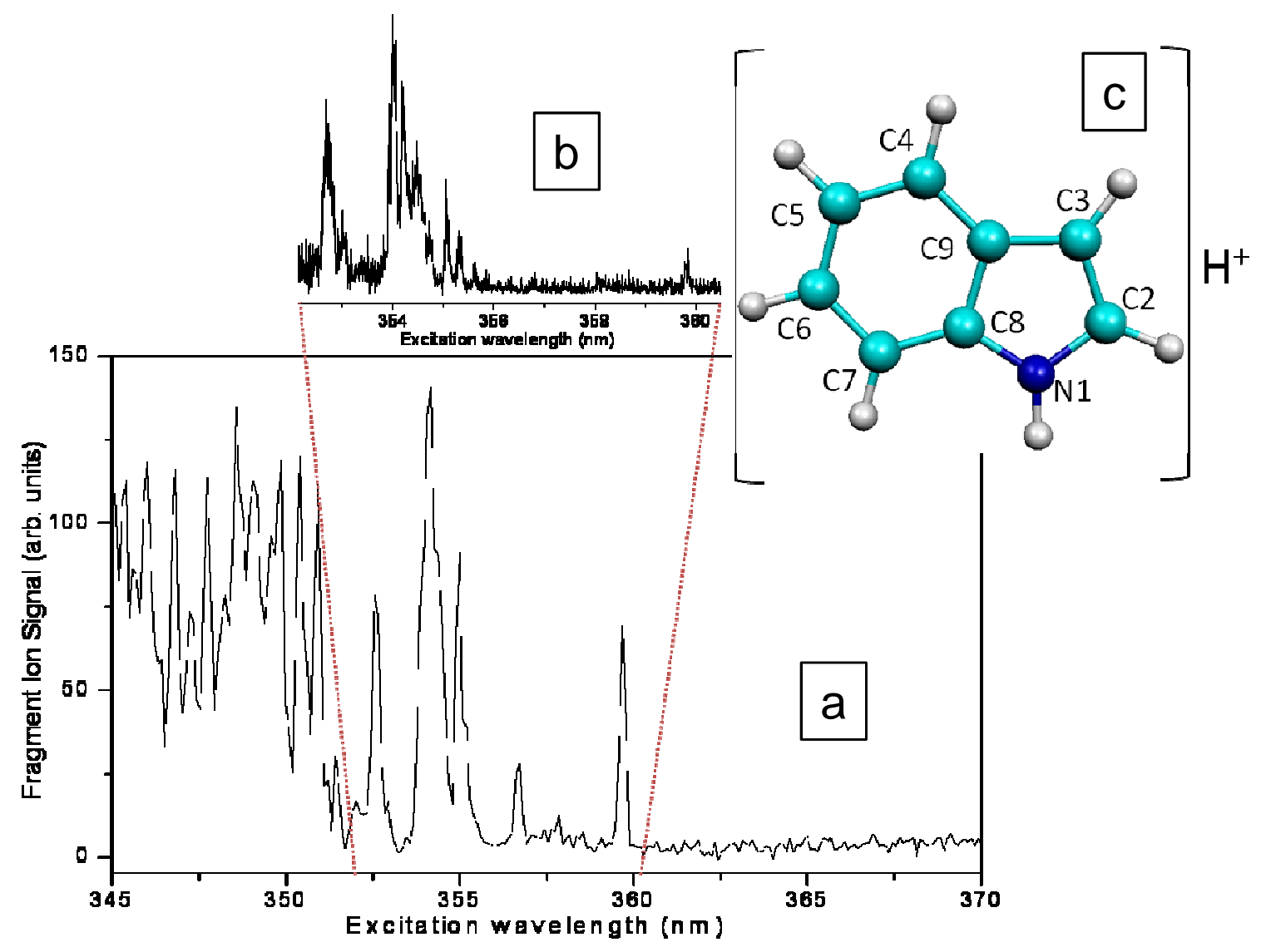

Figure 1 


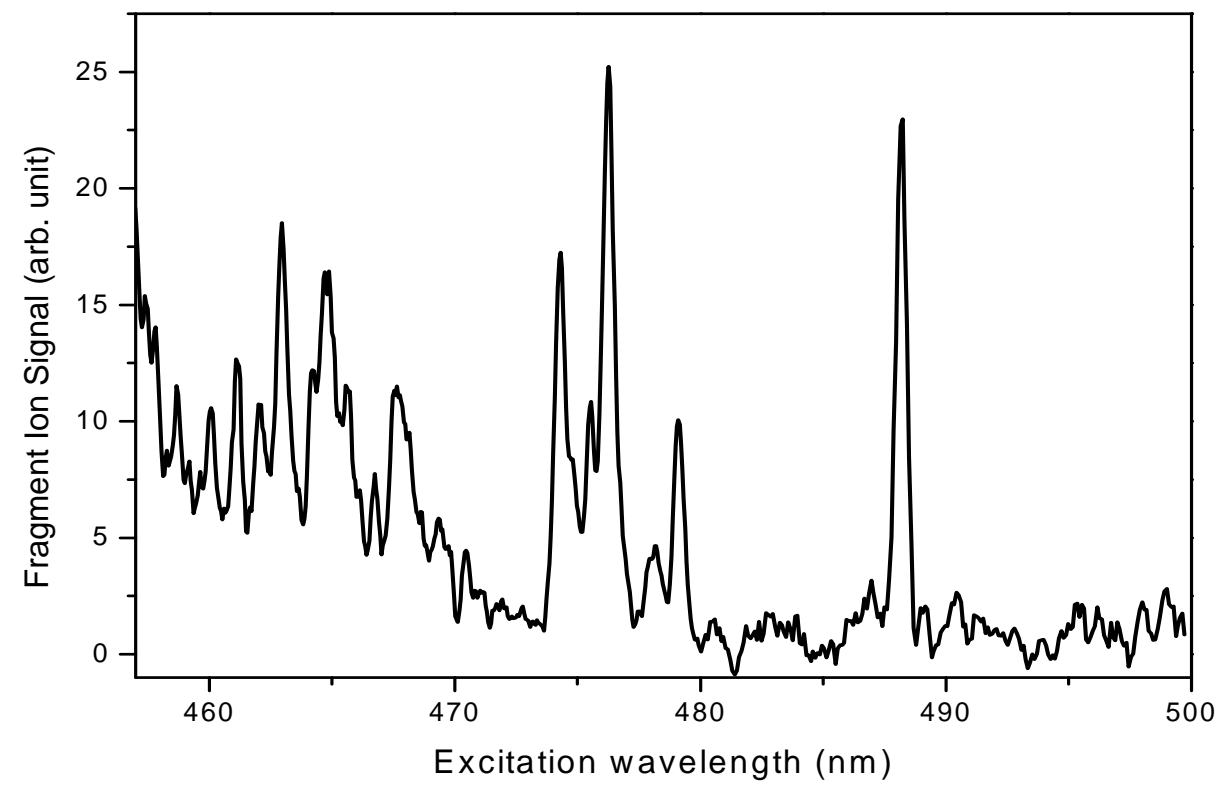

Figure 2 


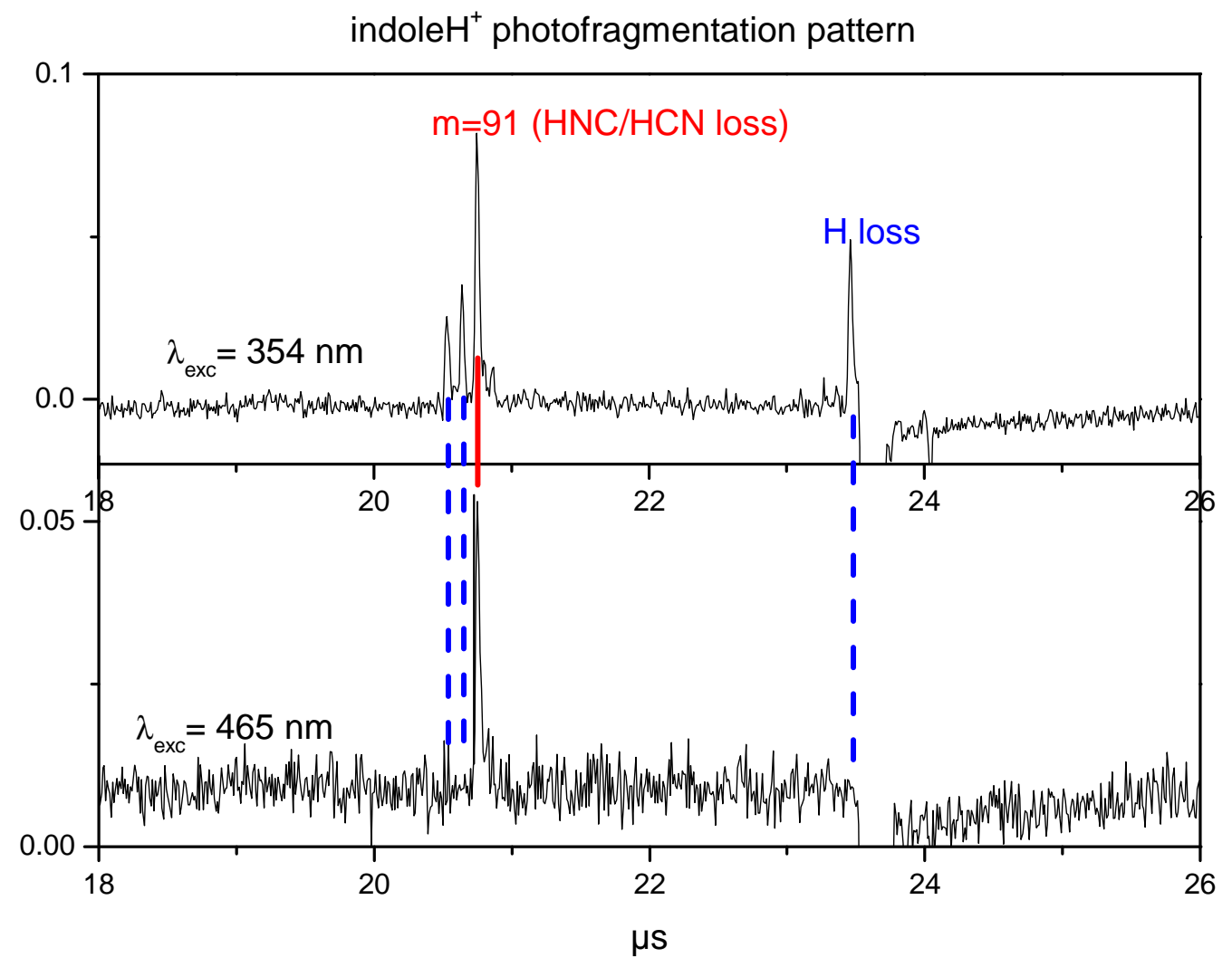

Figure 3 


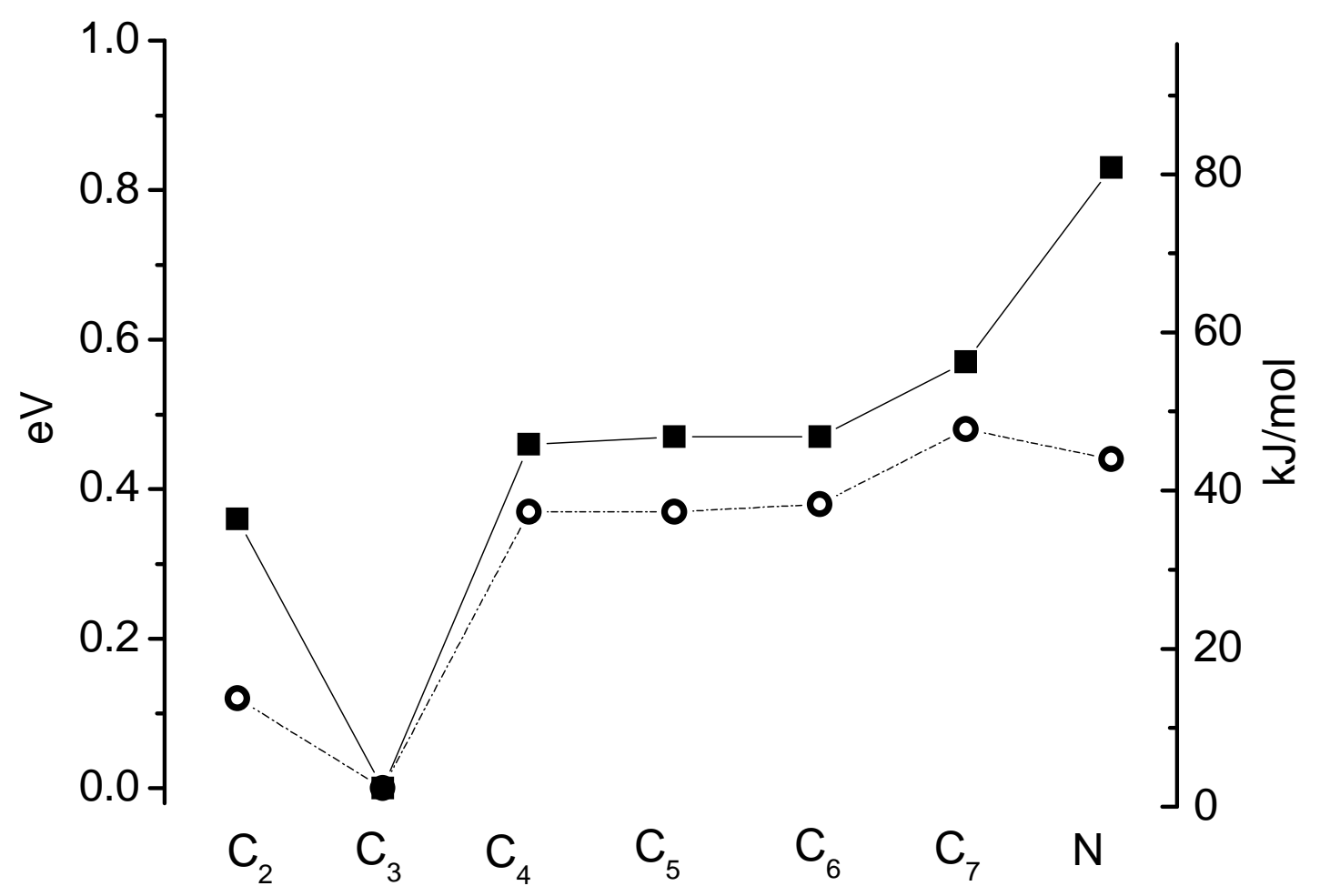

Figure 4 


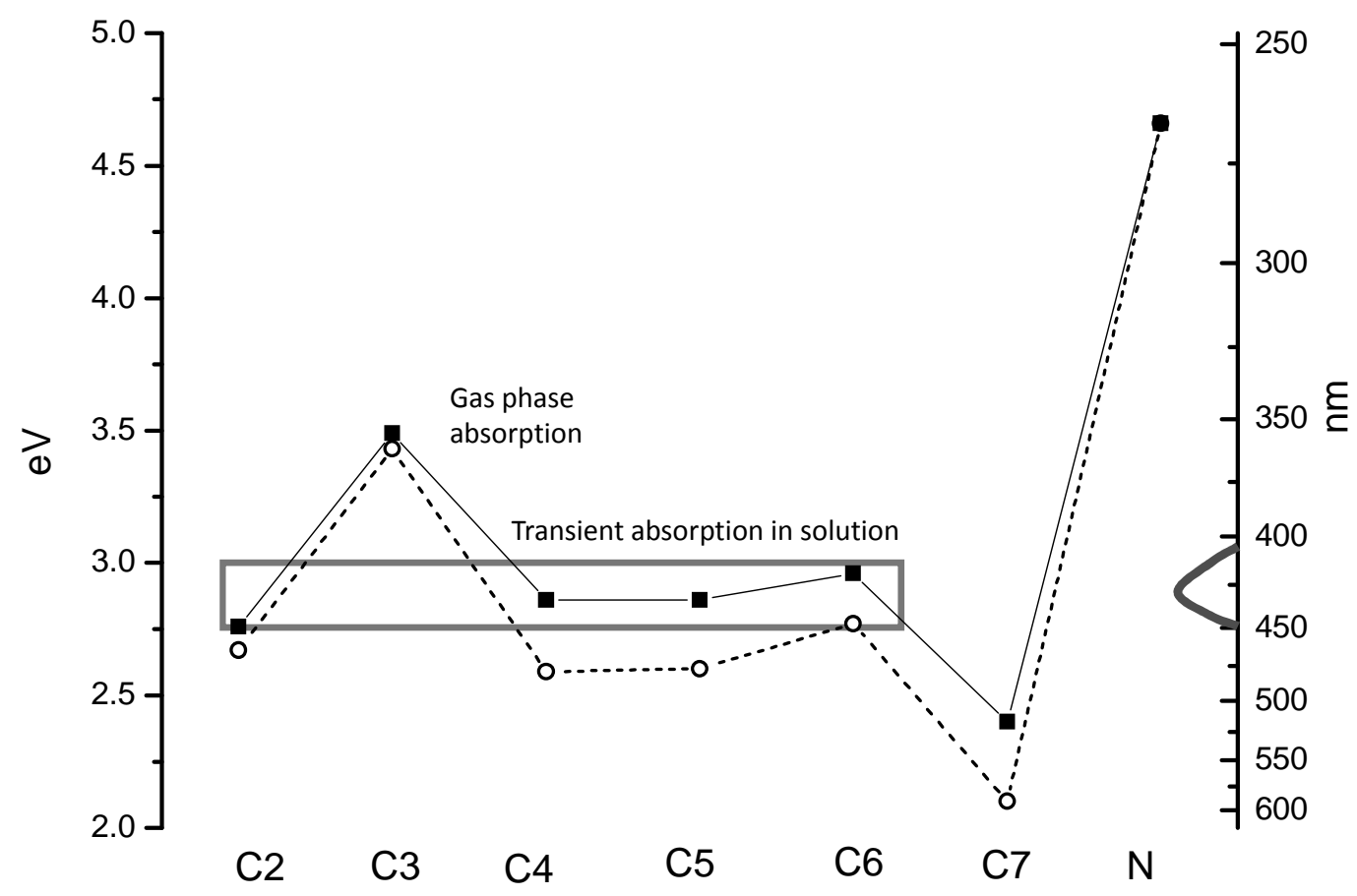

Figure 5 


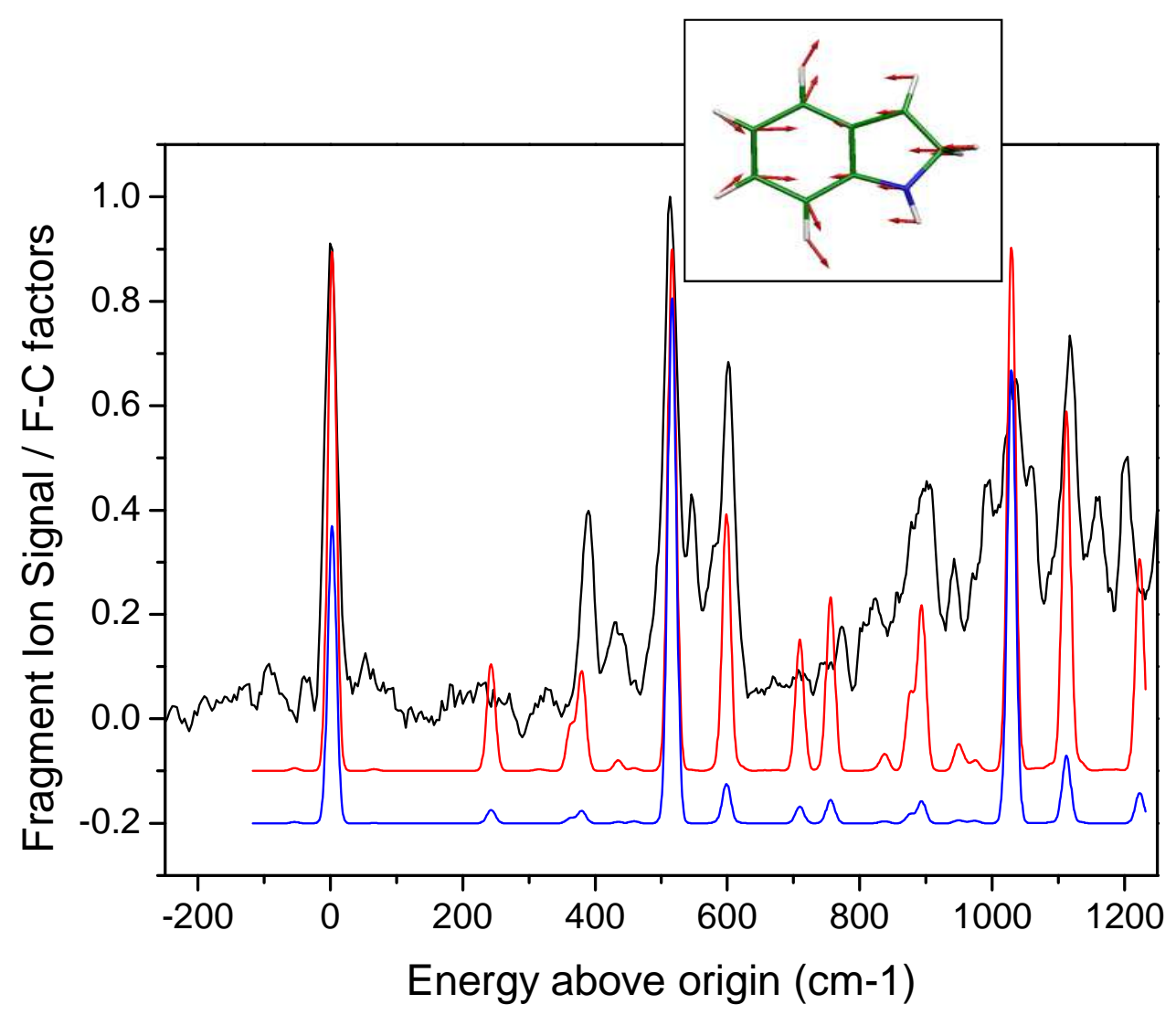

Figure 6 


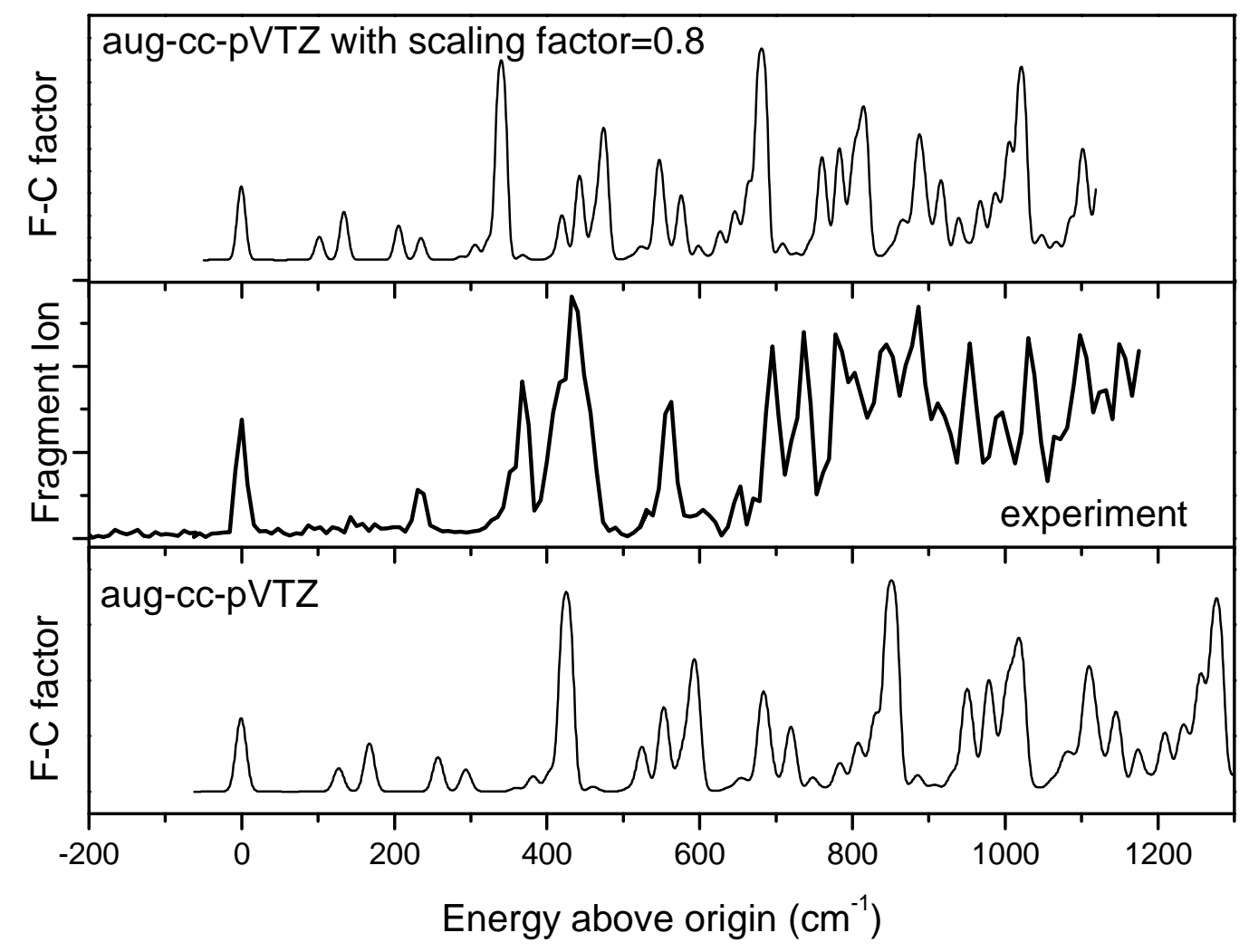

Figure 7 
TOC

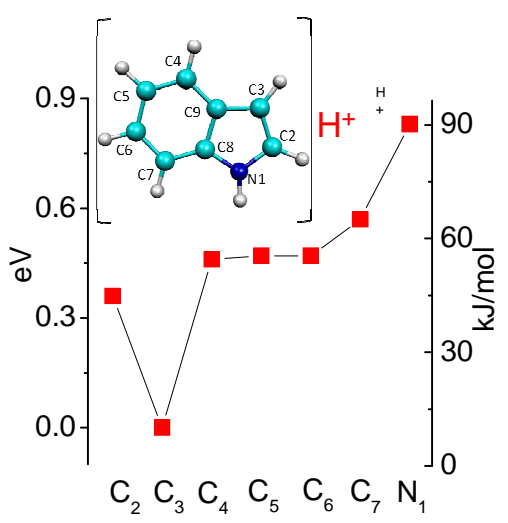

